University of South Florida

DIGITAL COMMONS

Digital Commons @ University of

@ UNIVERSITY OF SOUTH FLORIDA

South Florida

3-16-2017

\title{
Consistency of Structural Color across Molts: The Effects of Environmental Conditions and Stress on Feather Ultraviolet Reflectance
}

Rebecca Lynn Windsor

University of South Florida, rwindsor@mail.usf.edu

Follow this and additional works at: https://digitalcommons.usf.edu/etd

Part of the Biology Commons

\section{Scholar Commons Citation}

Windsor, Rebecca Lynn, "Consistency of Structural Color across Molts: The Effects of Environmental Conditions and Stress on Feather Ultraviolet Reflectance" (2017). USF Tampa Graduate Theses and Dissertations.

https://digitalcommons.usf.edu/etd/6782

This Thesis is brought to you for free and open access by the USF Graduate Theses and Dissertations at Digital Commons @ University of South Florida. It has been accepted for inclusion in USF Tampa Graduate Theses and Dissertations by an authorized administrator of Digital Commons @ University of South Florida. For more information, please contact digitalcommons@usf.edu. 
Consistency of Structural Color across Molts: The Effects of Environmental Conditions and Stress on Feather Ultraviolet Reflectance

by

\author{
Rebecca L. Windsor \\ A thesis submitted in partial fulfillment \\ of the requirements for the degree of \\ Master of Science \\ with a concentration in Ecology and Evolution \\ Department of Integrative Biology \\ College of Arts and Sciences \\ University of South Florida \\ Co-Major Professor: Reed Bowman, Ph.D. \\ Co-Major Professor: Gordon Fox, Ph.D. \\ Stephen Deban, Ph.D. \\ Date of Approval: \\ March 20, 2017
}

Keywords: Aphelocoma coerulescens, scrub-jay, UV color, plumage consistency, corticosterone

Copyright @ 2017, Rebecca L. Windsor 


\section{DEDICATION}

This work is dedicated to the jays, who captured my heart from the start, and who will hopefully continue to capture hearts for decades to come. 


\section{ACKNOWLEDGEMENTS}

This work would not have been possible without the constant support of my advisors, Reed and Gordon, who tirelessly answered all of my questions and gave me input. I thank Archbold Biological Station and the Cornell Lab of Ornithology for continued lodging and research support. Project guidance and emotional support were provided by Shane Pruett and Angela Tringali, who helped convince me that I really was a competent member of the field. Corticosterone administration guidance was provided by Stephen Schoech, Thomas Small, Emily Elderbrock, and Blake Jones. I also want to thank Lynn Siefferman, who provided endless guidance and troubleshooting advice on the spectrometer. Lastly, thank you to the countless interns and collaborators who helped collect data for the demography project at Archbold Biological Station. 


\section{TABLE OF CONTENTS}

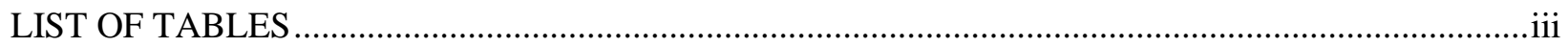

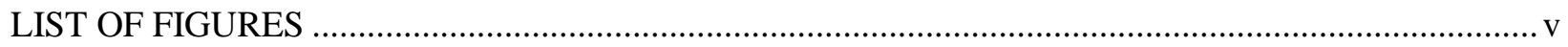

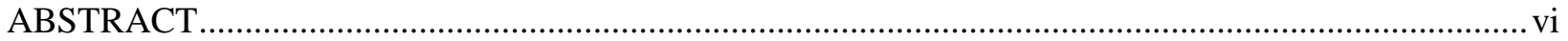

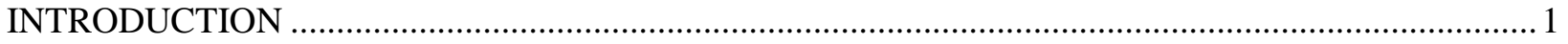

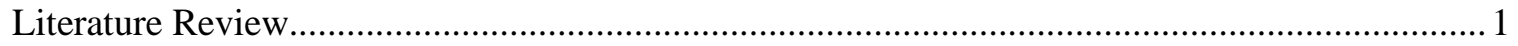

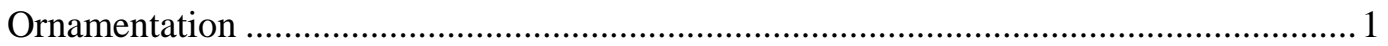

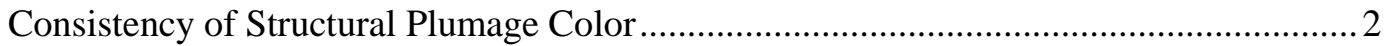

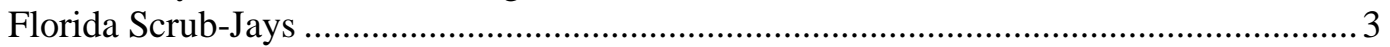

Effects of Environmental Conditions on Plumage Variation............................................5

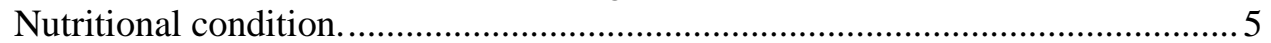

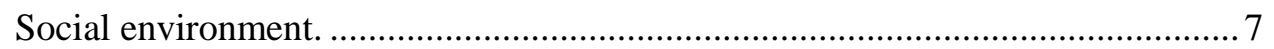

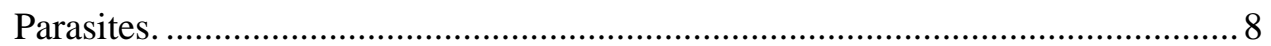

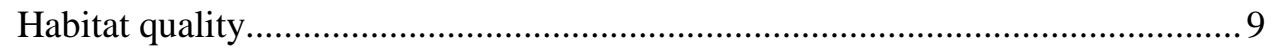

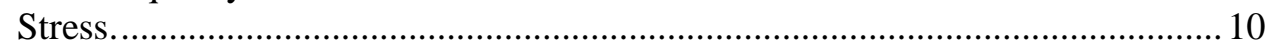

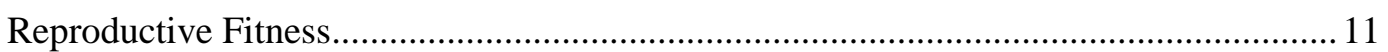

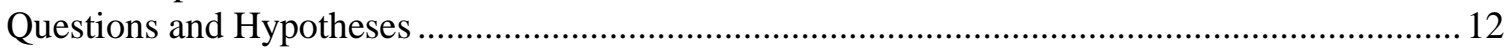

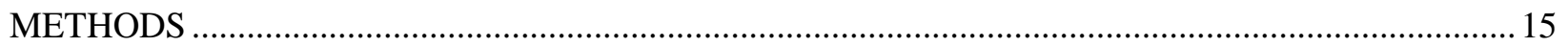

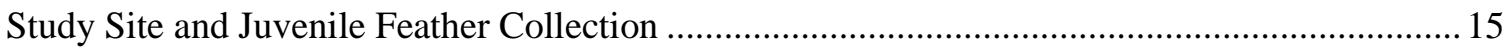

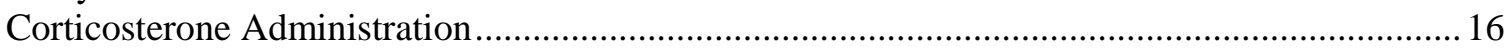

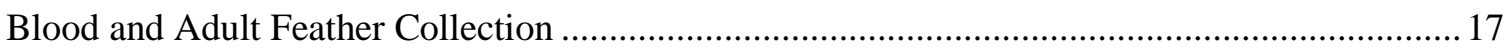

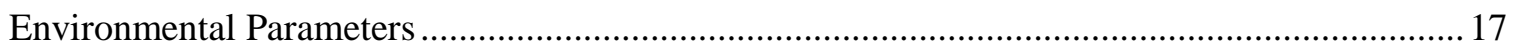

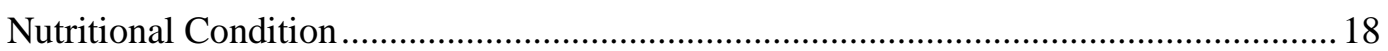

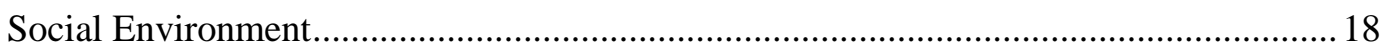

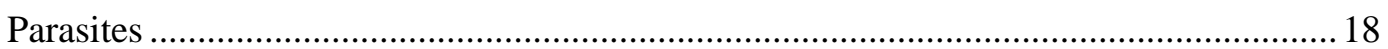

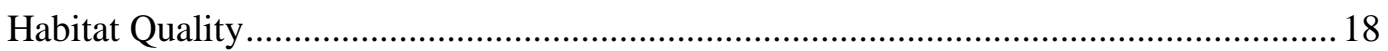

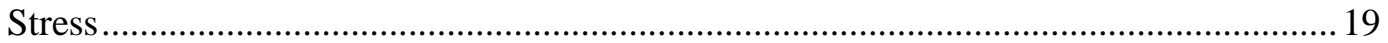

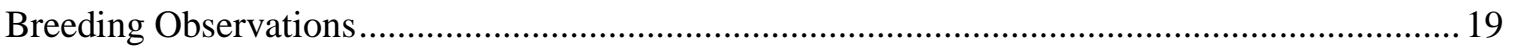

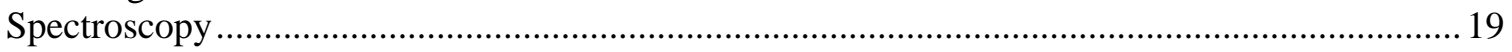

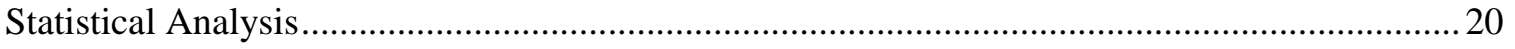

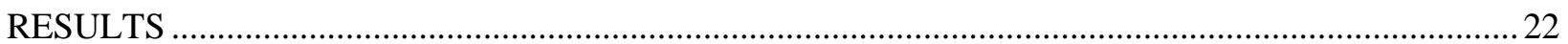

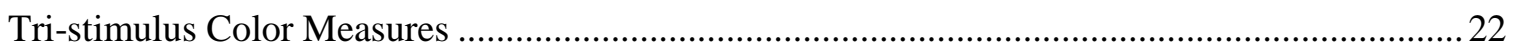

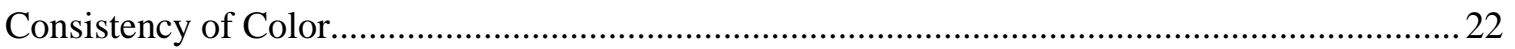

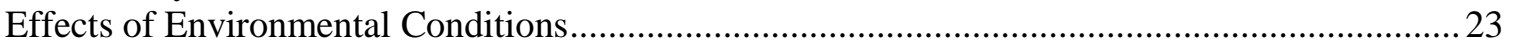

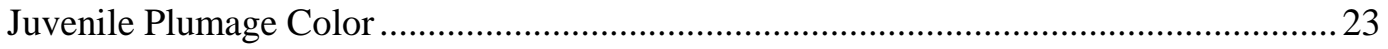

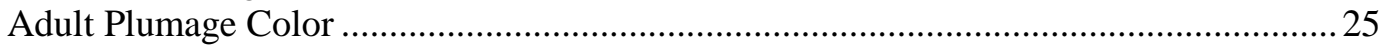

Relative Change in Plumage Color .............................................................................2 27

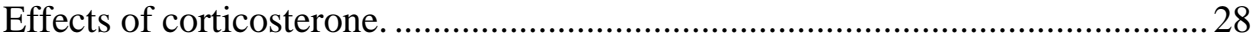




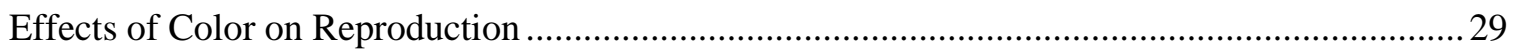

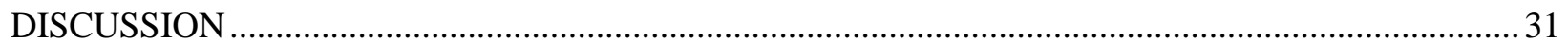

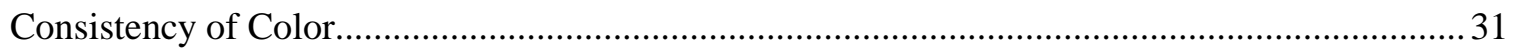

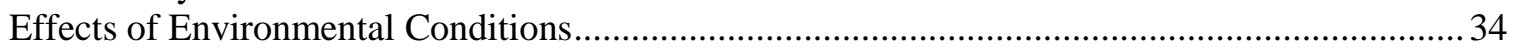

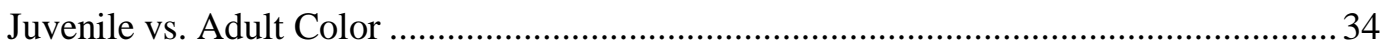

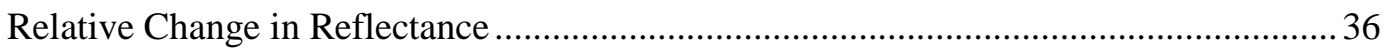

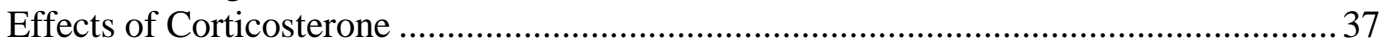

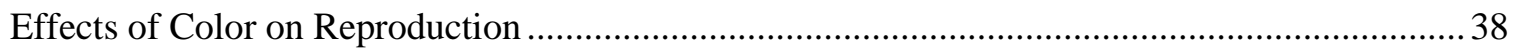

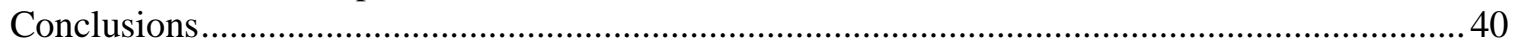

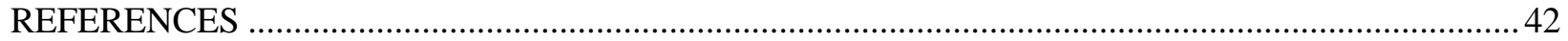

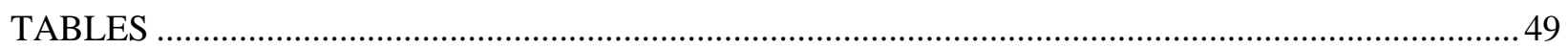

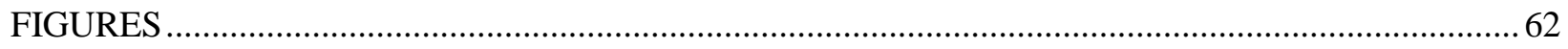

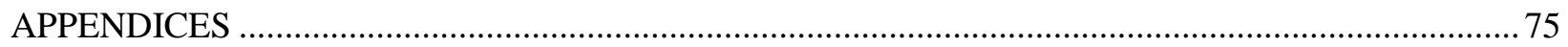

Appendix A: Effects of Individual Variables on Florida Scrub-Jay Rectrix Color ....................... 76 


\section{LIST OF TABLES}

Table 1. Mean ( \pm SD) color measures of juvenile and adult Florida Scrub-Jay rectrices .................... 49

Table 2. Linear mixed model of the top parameters that explain variation in juvenile

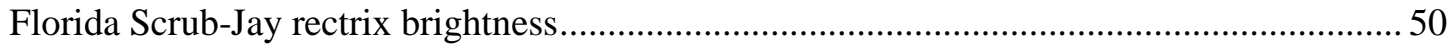

Table 3. Linear mixed model of the top parameters that explain variation in juvenile

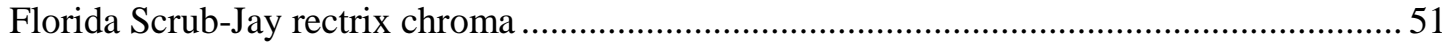

Table 4. Linear mixed model of the top parameters that explain variation in juvenile

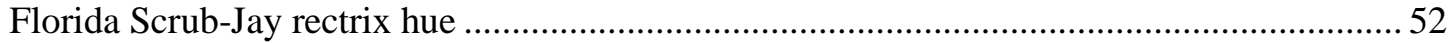

Table 5. Generalized linear model of the top parameters that explain variation in adult

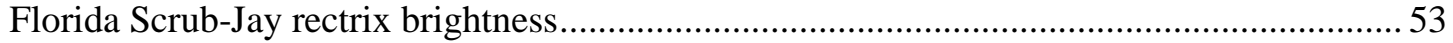

Table 6. Generalized linear model of the top parameters that explain variation in adult

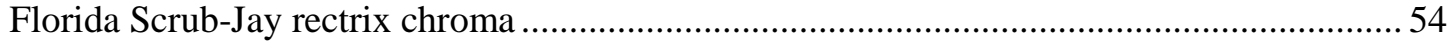

Table 7. Generalized linear model of the top parameters that explain variation in adult

Florida Scrub-Jay rectrix hue

Table 8. Generalized linear model of the top parameters that explain variation in relative

change in Florida Scrub-Jay rectrix brightness

Table 9. Generalized linear model of the top parameters that explain variation in relative change in Florida Scrub-Jay rectrix chroma

Table 10. Generalized linear model of the top parameters that explain variation in relative change in Florida Scrub-Jay rectrix hue

Table 11. Generalized linear model (binomial distribution, logit link function) of adult color variables that predict breeding fate

Table 12. Generalized linear model (binomial distribution, logit link function) of juvenile color variables that predict breeding fate

Table 13. Generalized linear model (binomial distribution, logit link function) of relative change in color variables that predict breeding fate

Table A1. Correlations of individual environmental variables on juvenile Florida Scrub-Jay brightness

Table A2. Correlations of individual environmental variables on juvenile Florida Scrub-Jay chroma 
Table A3. Correlations of individual environmental variables on juvenile Florida Scrub-Jay hue

Table A4. Correlations of individual environmental variables on adult Florida Scrub-Jay brightness

Table A5. Correlations of individual environmental variables on adult Florida Scrub-Jay chroma

Table A6. Correlations of individual environmental variables on adult Florida Scrub-Jay hue

Table A7. Correlations of individual environmental variables on relative change in Florida Scrub-Jay brightness.

Table A8. Correlations of individual environmental variables on relative change in Florida Scrub-Jay chroma

Table A9. Correlations of individual environmental variables on relative change in Florida Scrub-Jay hue 


\section{LIST OF FIGURES}

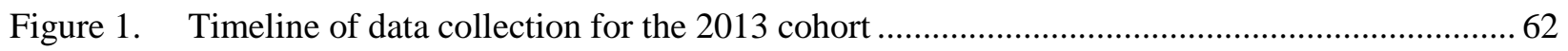

Figure 2. Correlations between the tri-stimulus color variables: brightness, chroma, and hue ............. 63

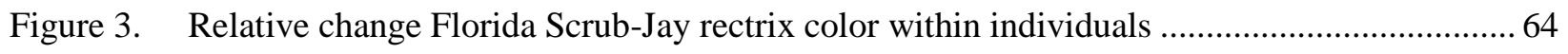

Figure 4. Relative change in Florida Scrub-Jay rectrix color within individuals for males and

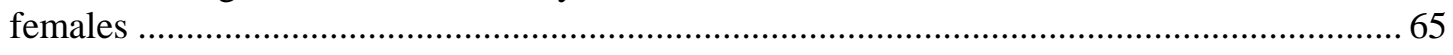

Figure 5. Juvenile vs. adult rectrix color in Florida Scrub-Jays within individuals $(n=57) \ldots \ldots \ldots \ldots \ldots \ldots . . . . . .66$

Figure 6. Juvenile vs. adult rectrix color in male and female Florida Scrub-Jays .............................. 67

Figure 7. Adult Florida Scrub-Jay rectrix color by corticosterone administration treatment

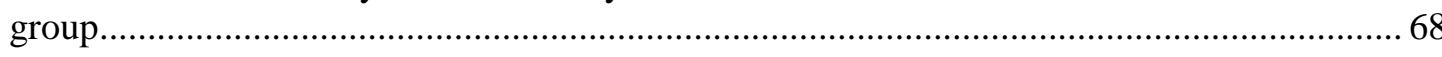

Figure 8. Male vs. female adult Florida Scrub-Jay rectrix color by corticosterone treatment group.

Figure 9. Relative change in Florida Scrub-Jay rectrix color across corticosterone treatment

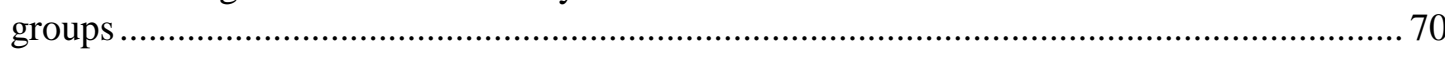

Figure 10. Juvenile vs. adult Florida Scrub-Jay rectrix color across corticosterone treatment groups: control $(n=19)$, experimental $(n=22)$, and sham control $(n=16)$.

Figure 11. Adult Florida Scrub-Jay rectrix color for individuals that became breeders vs. individuals that remained helpers

Figure 12. Juvenile Florida Scrub-Jay rectrix color for individuals that became breeders vs. individuals that remained helpers in their third year.

Figure 13. Relative change in Florida Scrub-Jay rectrix color for individuals that became breeders vs. individuals that remained helpers. 


\begin{abstract}
Across avian systems, plumage ornamentation is often considered a signal of individual fitness, condition, sex, or status, and varies due to genetics or environmental sources. In species with structural coloration, plumage variation results from differences in the amount of energy allocated to feather growth during molt, presenting a unique opportunity to study the link between individual quality and ornamentation. In cooperative breeding species, such as the Florida Scrub-Jay (Aphelocoma coerulescens), the role of structural color as a signal is particularly important because helpers may delay breeding for one to several years and competition for space is high. Florida Scrub-Jay juveniles are sexually dimorphic in the ultraviolet range, and plumage color predicts social dominance and condition, but not adult reproductive fitness. Little is known about the consistency of ultraviolet reflectance across molts, and I tested the following questions: 1) does plumage color change across molts within individuals; 2) how do environmental variables and stress affect structural color; and 3) does adult color or change in color predict reproductive fitness?
\end{abstract}

I measured relative change in color within individuals by comparing their juvenile and first set of adult feathers after pre-basic molt. I used several measures of nutritional condition, social dynamics, habitat quality, and parasite infection to model color, and I experimentally administered corticosterone during pre-basic molt to examine the effects of increased stress on color. Plumage reflectance was compared with breeding status to investigate the role of color in breeding space acquisition.

Plumage reflectance was significantly different within individuals across molts, but juvenile and adult color were correlated. Adults were significantly less bright than juveniles, with higher proportions of UV chroma and hues shifted toward UV wavelengths. Variation in feather color was best explained by sex, mass, parasite infection, and an interaction between area of oak scrub and group size. Juvenile feather 
color was also strongly associated with mother ID, but this was not the case for adults even though adult color was correlated with juvenile color. Adult chroma was reduced in birds treated with corticosterone, and hues were shifted toward longer wavelengths.

No measure of adult color predicted acquisition of breeding space, but change in brightness and hue were significant predictors of acquisition for females, where breeders tended to experience greater reductions in brightness and shifts toward UV hues compared to helpers. This may be due to sex-specific differences in reproductive strategies in Florida Scrub-Jays. Females tend to disperse farther distances and breed earlier than males, potentially expending more energy foraying and searching for breeding space, which could reduce brightness if it is linked with condition. These results suggest that sexual selection is not a dominant factor in plumage ornamentation for Florida Scrub-Jays, and understanding the interaction between plumage color, personality, and reproductive fitness should be a priority for future research. 


\section{INTRODUCTION}

\section{Literature Review}

\section{Ornamentation}

Ornamental traits function as signals to conspecifics, indicating social status, fitness, condition, etc., and are an important component in sexual selection (Andersson and Iwasa 1996). However, elaborate ornaments are costly to produce and maintain, and honest-signaling theory predicts that only high quality individuals are able to produce exaggerated ornamental displays (Zahavi 1975, Kodric-Brown and Brown 1984). Quality of an individual often includes measures of several phenotypic or genetic components, including resistance to disease or parasites, competitive behavior, or condition (Andersson 1994). To better understand the link between individual quality and ornamentation, it is essential to examine how genetic or environmental conditions influence individual variation in ornamentation. The present study examines sources that contribute to variation in ornamentation and potential implications of this variation on reproductive success.

Signaling through ornamental plumage displays has been well documented in avian species (see review in Hill and McGraw 2006), but little is known about the consistency of ornamental traits throughout an individual's lifetime. In birds, feathers come in a variety of colors resulting from either biochrome pigments (carotenoids, melanins, porphyrins) or the actual structure of the feathers themselves (Hill and McGraw 2006, Gill 2007). Carotenoid and melanin pigments are widespread and well-studied among avian taxa, and are deposited in feathers through molecules either ingested from the environment or synthesized by amino acid precursors (McGraw 2006a, b). Because of its dependence on diet, variation in carotenoid-based plumage appears to be linked with nutritional and physical condition (Hill 2000, Bortolotti et al. 2009) and is important in sexual selection (McGraw 2006a). Conversely, melanin-based 
plumage is important in signaling mate quality or aggressiveness (McGraw et al. 2003, McGraw 2006b), and variation results from behavioral interactions during feather development (McGraw et al. 2003, Laucht and Dale 2012), but not nutrition (McGraw et al. 2002).

Unlike biochrome pigments which are continuously being produced and deposited in feathers, structural color results from the interaction of light with the arrangement of keratin rods within feather barbs, often producing ultraviolet (UV) color (Shawkey et al. 2003, Prum 2006). These nanostructures require precise construction and arrangement to produce color, and the number of protein rods is correlated with feather UV chroma (Shawkey et al. 2003). Birds can see in the UV spectrum and are able to differentiate between subtle variations in UV color, where even small variations can produce visibly distinct colors (Derim-Oglu and Maximov 1994). In species with structural coloration, plumage variation results from differences in energy allocated to feather growth due to environmental conditions during molt, where birds that grow feathers faster have brighter, more ornamented feathers (Prum 2006, Siefferman et al. 2008). Habitat quality, diet, social hierarchy, and parasite levels all can affect an individual's energy levels and thus feather growth, making it an honest signal since birds with large energy budgets can invest more in feather development (Hamilton and Zuk 1982, Grubb 2006, Hill 2006, Grindstaff et al. 2012). Structural color could therefore result from and signal an individual's condition or resiliency to stressors (Doucet and Montgomerie 2003, Grindstaff et al. 2012; but see Peters et al. 2011), making it a useful indicator of individual and population health.

\section{Consistency of Structural Plumage Color}

Most avian species molt at least once a year, and variation in feather growth due to environmental conditions implies that plumage quality (e.g. feather mass, color reflectance, saturation) may not be consistent from year to year. Furthermore, adult plumage is often of higher quality than juvenile plumage, and signals may differ between plumages of differing life stages (Prum 2006). To my knowledge, few studies have directly compared feathers between molts to examine sources of change and consistency of ornamentation. Hegyi et al. (2015) showed that several ornamental plumage traits in free- 
living Great Tits (Parus major) were consistent across seasons and years, but in two experiments with free-living Blue Tits (Cyanistes caeruleus), UV reflectance within individuals differed across molts. When adults received testosterone implants (Roberts et al. 2009) or had their first clutches removed forcing them to re-lay a second clutch (Doutrelant et al. 2012), UV reflectance changed across molts and reflected observed differences in hormone levels and reproductive effort, respectively. Evidence also exists that structural color changes in response to parasite levels. Steller's jays (Cyanocitta stelleri) treated for parasites and disease prior to molt grew feathers that were $10 \%$ brighter than those of control birds (Zirpoli et al. 2013). These studies suggest that structural color is sensitive to a variety of environmental conditions and is a plastic phenotypic trait.

It is important to note that structural color also can change in the time between molts. UV color decreases with time since molt, possibly due to wear and fat deposition (Avilés et al. 2008, Roberts et al. 2009). Keratinolytic bacteria also can degrade feathers over time, and birds with higher bacterial loads often have brighter color (feral pigeons (Columba livia): Leclaire et al. 2014, Eastern Bluebirds (Sialia sialis): Shawkey et al.2007). In a lab setting, inoculated bacteria degrade the exterior cortex of feathers, exposing the spongy layer and increasing feather brightness (Shawkey et al. 2007). Bacteria also can reduce UV chroma, but do not appear to affect the dimensions nor composition of the spongy layer (Shawkey et al. 2007). This is puzzling because UV chroma is linked with proteins in the spongy layer (Shawkey et al. 2003). The disconnect between chroma and bacterial infection may be due to the combination of a lack of change in the spongy layer and the overall increase in brightness, thus affecting the proportion of UV chroma. While I recognize the agents that can affect feather quality and color in the time between molts, they are outside the limits of this study. I focused on environmental conditions at the time of molt that can affect consistency of UV coloration in a well-studied species, the Florida Scrub-Jay.

\section{Florida Scrub-Jays}

Endemic to Florida, the Threatened Florida Scrub-Jay (Aphelocoma coerulescens, hereafter FSJ) inhabits the diminishing, fire-maintained oak scrub habitat that occurs on the Lake Wales Ridge and relict 
sand dunes elsewhere on peninsular Florida. FSJs are cooperative breeders that form family groups consisting of a monogamous breeder pair and 1-6 helpers which are most often offspring from previous seasons, but can include unrelated individuals (Woolfenden and Fitzpatrick 1984). FSJ families establish and follow strict hierarchies, where breeders dominate helpers, males dominate females, and older birds tend to dominate younger birds (Woolfenden and Fitzpatrick 1977). Helpers aid with vigilance, territorial defense, and nestling/fledgling provisioning (Woolfenden and Fitzpatrick 1990).

Groups defend permanent territories year-round, and obtaining territory space is necessary for nesting, foraging, and over-winter survival (Woolfenden and Fitzpatrick 1984). Jays often foray in the early spring or late fall to search for breeding space openings, resulting in intense scramble competitions. Because unoccupied space is limited, territories are most often acquired by replacement of a breeder, either through inheritance by a male heir or dispersal to a different territory. If a territory is large enough, young males can also gain part of their fathers' territories to start their own, referred to as "territorial budding" (Woolfenden and Fitzpatrick 1978). Rarely, new pairs attempt to forge their own territory in vacant locations, called de novo territory formation, but this requires the pair to establish a pair bond prior to enforcing territory boundaries with neighboring groups, a process that can take months to complete (Woolfenden and Fitzpatrick 1984).

The jays have predominantly blue structural plumage, and both adults and juveniles are sexually dimorphic in the UV spectrum (Bridge et al. 2007, Siefferman et al. 2008). When competing for breeding space and participating in dominance encounters, jays fan their tails and hop around each other in a lateral display (Woolfenden and Fitzpatrick 1996), suggesting that rectrices act as a signal. UV chroma predicts condition in juveniles (Siefferman et al. 2008), and experimental reductions in rectrix reflectance caused those individuals to lose a greater proportion of dominance interactions (Tringali and Bowman 2012). However interestingly, UV brightness, chroma, and hue were not significantly correlated with dominance in FSJ juveniles, and do not predict adult reproductive fitness (Siefferman et al. 2008, Tringali and Bowman 2012). This suggests that FSJ plumage color may not be consistent across molts. Most FSJs 
begin breeding at 2-3 years of age, after their first pre-basic molt into adult plumage (Woolfenden and Fitzpatrick 1990), which occurs in August, when the birds are about 1.5 years old. Because FSJs only molt once a year, environmental conditions during molt can have considerable effects on reproductive fitness since feathers are retained through the period in which these birds are competing for breeding opportunities during the following February and March (Bancroft and Woolfenden 1982).

\section{Effects of Environmental Conditions on Plumage Variation}

Hill (2006) outlined four classes of environmental factors that affect ornamental plumage displays: pigment access, nutritional condition, social environment, and parasites. The effect of dietary pigment access is limited to carotenoid-based color displays, thus I focused on the latter three environmental factors and added a fifth potential factor, habitat quality. Furthermore, I examined the role that stress plays in structural plumage color variation, and how it interacted with other environmental variables to affect plumage.

Nutritional condition. In birds with structural color, two primary methods for examining the effects of nutritional condition on plumage exist: ptilochronology and physical condition. Ptilochronology measures variation in feather growth bars, specifically nutrition's effects on feather growth rate, which is considered an honest and accurate signal of individual condition and health (Grubb 1989, 2006). Birds that have better nutrition are able to grow better quality feathers faster, and UV reflectance is positively correlated with feather growth rate (Keyser and Hill 1999, Doucet and Montgomerie 2003). Feather growth bars also can be used to determine the degree of fluctuating asymmetry (FA) within an individual, which consists of small deviations from bilateral symmetry (Ludwig 1932). FA is sensitive to the effects of environmental or genetic stress and is also a good indicator of individual quality (Parsons 1990, Lens and Eggermont 2008). In a review of FA literature, Møller (1997) found a negative correlation between individual fitness (e.g. growth, fecundity, and longevity) and developmental instability. Higher levels of asymmetry also can reduce aerodynamic performance (Swaddle 1997) and UV reflectance (Galván 2011). I will measure FA and fault bar occurrence, feather regions with reduced barbule density, to use as 
estimates of nutritional stability for comparisons with UV reflectance since they negatively covary in other species (Galván 2011, Grubb 2006).

The effects of nutrition on plumage also can be examined indirectly through an individual's body condition (e.g. fat, mass). Because structural coloration is derived from the precise assembly of nanostructures within each feather (Shawkey et al. 2003, Prum 2006), nutrition and body condition during molt are likely very important. However, evidence for correlations between body condition and feather quality is mixed. Several studies have documented positive correlations between body condition and UV color (Satin Bowerbirds (Ptilonorhynchus violaceus): Doucet and Montgomerie 2003, Eastern Bluebirds: Grindstaff et al. 2012), and in an experiment using food-stressed conditions during molt, McGraw et al. (2002) found that Brown-Headed Cowbirds (Molothrus ater) grew significantly less saturated and bright structural, iridescent plumage. Conversely, no correlation appears to exist between body condition and UV signal in Blue Tits (Henderson et al. 2013; but see Johnsen et al. 2003). Peters et al. (2011) tried a similar diet experiment in Blue Tits and found no correlation between individual body condition and UV reflectance. Interestingly, McGraw et al. (2002) used a stressful nutrition treatment whereas Peters et al. (2011) compared an enhanced diet to a standard one; thus, perhaps the effects of nutrition on structural UV color and are only apparent in stressful nutritional conditions.

Currently, much of the ptilochronology work on FSJs had been conducted on juveniles, and shows that feather growth bar width and feather mass act as accurate indices of nutritional condition (Grubb et al. 1998, Siefferman et al. 2008). Mass is positively correlated with feather growth bar width and hatch date, and growth bar width was also positively correlated with UV chroma (Grubb et al. 1998, Siefferman et al. 2008). This suggests that variation in plumage color, specifically UV chroma, is condition-dependent. It is possible that some genetic covariation exists between mass and plumage color or a heritable component (Johnsen et al. 2003), but this has not yet been studied in FSJs. The present study focuses on mass as a measure of nutritional condition, and ptilochronology and FA will be addressed in future publications. 
Social environment. The effects of social conditions on plumage have not been as well studied, especially in species with structural color. According to Hill (2006), social environment could affect color production in three ways: (1) competition over food that ultimately impacts nutrition, (2) effects of group living on parasite abundance, and (3) regulation of hormone levels through social interactions. In social species, dominant individuals often have better nutritional condition than subordinates (Grubb 2006), and therefore would have better quality plumage, as mentioned in the previous section on nutrition. While the indirect effects of social environment on parasites will not be addressed in my study, parasite levels on an individual basis will be included and described in the following section on parasites. Finally, because the FSJ is a cooperative breeder with complex social dynamics, I also will focus on the social correlates of plumage consistency, such as group size.

In a cooperatively breeding species like the FSJ where there are strict dominance hierarchies, family group dynamics could have profound effects on plumage quality. Sibling interactions in particular could have early effects on an individual's place in the family hierarchy, and as a result, its plumage quality during molt. Since males dominate females, and older males dominate younger males (Woolfenden and Fitzpatrick 1977), birds with older brothers would likely receive increased aggression levels compared to birds without any older brothers, potentially reducing feather quality. Birds in large families may face greater competition for food which could result in poor nutritional condition and plumage, especially in territories without enough oak scrub (Mumme et al. 2015). But in high quality territories with enough resources, having a large family may be beneficial since more individuals would be available to share sentinel duties, allowing jays more time to forage, potentially improving condition and reducing stress associated with predation risk (McGowan and Woolfenden 1989).

A second social component that jays may encounter within their family groups is the degree of relatedness with other birds, specifically the breeders. In cases where a breeder is replaced, helpers can sometimes receive abnormally high aggression levels from replacement breeders, particularly from jays of the same sex (Woolfenden and Fitzpatrick 1977). When comparing aggression rates between step- 
parents and same sex non-breeders to parents and their same sex offspring, Goldstein et al. (1998) found support for the dominance hypothesis, where step-parents perceive same sex non-breeders as competitors for mates and behave accordingly. As a result, significantly fewer one-year-old males remained home with a step-father, and the same was observed for females and step-mothers (Goldstein et al. 1998). For non-breeding jays with a low degree of relatedness within a family group (i.e. jays with step-parents, adopted helpers), increased aggression from those unrelated individuals can increase stress levels, reducing feather quality. Similarly, aggression levels may also be higher for individuals in groups among less closely related or familiar neighbors, as described by the 'Dear Enemy Hypothesis' (Temeles 1994, Kellett and Bowman unpub. data).

Lastly, feather UV reflectance appears to be linked with maternal effects in FJSs (Tringali et al. 2015). Mean brightness and UV chroma are both heritable, either through inheritance from the female breeder or behavioral differences between female breeders, such as provisioning or defense from predators. As a result, natal social environment likely has strong and long-lasting effects on FSJ feather color, that could affect competition for resources as well as breeding space.

Parasites. Parasite load can negatively affect plumage, and correlations have been found in several species with structural color (Harper 1999, Doucet and Montgomerie 2003, Hill et al. 2005). In the FSJ, parasites are relatively common. Fifteen species of helminth worms have been documented in FSJs, the most dominant of which includes one trematode, four nematodes, and one acanthocephalan (Kinsella 1974). Many adult individuals had multiple infections with three or more species, and no adult was free from infection (Kinsella 1974). Many of these endoparasites have two stages of development in both the tissues and bloodstream, and are mainly transmitted through biting arthropods (Kinsella 1974, Atkinson and van Riper 1991). Recent work has primarily focused on two focal hemotropic endoparasites and their distributions in the study population at Archbold Biological Station: a filarid worm (Aproctella sp.) and trypanosomes (species unknown). Preliminary data show a negative correlation between reproductive success and microfilariae, but not trypanosomes (Robbins et al., in prep). Furthermore, 
juveniles from natal territories containing a larger proportion of wet habitat have higher rates of microfilariae and trypanosome infection (Robbins et al., in prep). This implies that endoparasite infections may be related to habitat quality and contribute to both reproductive and habitat-related stress, which would likely affect plumage development.

Habitat quality. Interactions with the surrounding ecosystem can have several potential consequences on plumage color. For example, access to food and resources can be limited by predator abundance, lack of cover, dry years, etc. Climate can influence insect abundance and ultimately drive changes in plumage color, often leading to annual variation within a population. In years with moderate temperatures and precipitation, Redstarts (Setophaga ruticilla) molted feathers with higher red chroma (Reudink et al. 2015) and Collared Flycatchers (Ficedula albicollis) grew larger forehead and wing patches (Hegyi et al. 2007). However, in drought years or overly wet years, insect abundance declines, resulting in reductions in body mass (Smith et al. 2010) and plumage color (Reudink et al. 2015). This illustrates that the size and color of ornaments are plastic traits influenced by habitat quality and weather. While I acknowledge the role that climate has on feather color, my focus was on within- and betweenindividual variation for three yearly cohorts of jays, and jays experienced the same weather conditions, thus weather variables were not included in my models.

In many avian species, individuals defend territories for at least part of the year that contain the necessary resources for breeding and survival (Brown 1969). The quality of habitat within a territory can ultimately affect reproductive success through food supply, nesting locations, and predator abundance (Vickery et al. 1992, Witter and Lee 1995). Depending on density, only the highest quality males will have access to high quality territories and habitats, and males with poor quality territories may not be able to reproduce (Fretwell and Lucas 1970). For example, adult male Black-headed Grosbeaks (Pheucticus melanocephalus) with bright plumage defended better quality habitats with fewer nest predators than duller males, and had greater reproductive success (Hill 1988). 
In a cooperatively breeding species like the FSJ that experiences delayed breeding, competition for limited high quality habitat is especially evident. The scrub ecosystem on the demography tract at Archbold Biological Station (ABS) contains a mosaic of seven microhabitats (southern ridge sandhills, sand pine scrub, scrubby flatwoods, flatwoods, swale, bayhead, seasonal ponds) which are created and maintained by fire (Abrahamson 1984, Abrahamson et al. 1984). FSJ territories can contain several of these microhabitats, but quality of the habitat within a territory may depend on several components, such as time since last fire (TSF) (Woolfenden and Fitzpatrick 1984, Breininger and Schmalzer 1990), amount of oak scrub (Mumme et al. 2015), and proximity to forests (Woolfenden and Fitzpatrick 1984, Breininger et al. 1995). Jays depend on oaks for nesting and acorns, and FSJ densities are higher in areas that burned within the last 2-9 years and have more oak scrub (Breininger and Schmalzer 1990, Breininger et al. 1995, Mumme et al. 2015). Furthermore, the area of oak scrub within a territory is positively correlated with juvenile body mass and the probability of becoming a breeder (Mumme et al. 2015), suggesting that birds with higher quality territories have greater reproductive fitness. Thus, since natal habitat quality affects juvenile mass, it also could affect feather growth and UV brightness.

Stress. Glucocorticoids are a group of steroid hormones that are secreted in vertebrates in response to stressful stimuli, and as a result are often used as physiological indices of condition (Sapolsky et al. 2000, Bonier et al. 2009). Corticosterone (CORT), the primary avian glucocorticoid, is a metabolic hormone that is secreted in response to an individual's energetic demands, forming the basis of the CORT-fitness hypothesis: individuals with higher baseline CORT levels are of lower quality due to difficulties coping with their environment (Angelier et al. 2010). This hypothesis depends on two primary assumptions: (1) baseline CORT increases with environmental challenges, and (2) fitness declines with increasing environmental challenges (Bonier et al. 2009). High CORT levels can have several negative consequences, including reduced immunosuppression (Sapolsky et al. 2000, Bortolotti et al. 2009) and reduced feather quality (DesRochers et al. 2008, Lattin et al. 2011), and can have long-lasting effects on condition and reproduction. CORT breaks down proteins, leading to lighter, weaker, and more slowly- 
growing feathers with altered nanostructures (DesRochers et al. 2008, Lattin et al. 2011), which is why it is typically downregulated during molt (Romero and Remage-Healey 2000, Romero et al. 2005). Because environmental conditions appear to have an important influence on condition in FSJs, I predict interactive effects between stress and environment in explaining variation in plumage.

CORT directly affects feather structure, and in birds with structural color, the associated increases in developmental instability, fault bar occurrence, and FA result in lower UV reflectance as well (DesRochers et al. 2008, Galván 2011). However, evidence for correlations between CORT and UV reflectance appear to be mixed. Henderson et al. (2013) observed a negative correlation between UV color and baseline CORT in female Blue Tits, but this was not the case in Eastern Bluebirds, where a positive correlation existed between CORT and UV hue and saturation (Grindstaff et al. 2012). In FSJs, Tringali and Bowman (2012) found that UV reflectance signals dominance in juveniles, and that the relative change in dominance was positively correlated with the relative difference in CORT (Tringali, pers. com.). Therefore, CORT seems to play a role in development of UV reflectance in FSJs, but this relationship may be indirect. CORT is negatively correlated with body mass in FSJs (Schoech et al. 1997), and supplemental food reduces baseline CORT levels (Schoech et al. 2004), suggesting that CORT and condition may interact and affect plumage.

Reproductive Fitness

Plumage quality can have considerable effects on lifetime reproductive fitness. In FSJs, most birds recruit into the breeding population in their second or third years, thus most molt at least once after their juvenile plumage before breeding (Bancroft and Woolfenden 1982, Woolfenden and Fitzpatrick 1984). Lifetime reproductive success increases with age (Woolfenden and Fitzpatrick 1984, Hewitt et al. 2006), thus the earlier a jay can begin breeding, the greater its chance of increased reproductive success. Also, experienced breeders produce more fledglings than novices (Woolfenden and Fitzpatrick 1984), thus early breeding jays gain breeding experience sooner, further increasing their potential lifetime 
reproductive fitness. The fitness advantages of breeding early in life emphasize the role of plumage quality and UV reflectance in intra-sexual competition and sexual selection.

\section{Questions and Hypotheses}

My study focused on consistency of FSJ UV reflectance across molts as well as environmental sources of change in UV reflectance. I combined observational and experimental approaches to test 1) does FSJ UV reflectance change across molts, 2) how do environmental conditions and experimentallydelivered CORT interact to affect feather coloration during growth, and 3) how do changes in UV reflectance affect reproductive fitness? I investigated how feather UV reflectance changes over time by using pair-wise comparisons of feathers collected from an individual's preformative molt (juvenile plumage) to those collected from its first pre-basic molt (adult plumage).

I predicted that UV reflectance within individuals would change across molts because condition at time of molt plays such a role in feather growth, and thus structural color. I expected a general increase in feather quality and UV reflectance with age (Prum 2006, Korsten et al. 2007, Doutrelant et al. 2012, Grindstaff et al. 2012) as well as some overall yearly variation (Henderson et al. 2013), but I predicted that environmental conditions would still have a measurable effect and would explain a considerable portion of the observed among- and between-individual variation in plumage. The first feather sample collected during the jays' preformative molts represented environmental conditions during the juvenile stage, including natal family effects, such as provisioning rates by parents, etc. The second feather sample, collected from the first pre-basic molt, represented any environmental conditions individuals experienced one year later, and better indicated each jay's individual condition since they were nutritionally independent.

Of the five classes of environmental variables outlined above, my analyses focused on factors that likely affected individuals' energy levels, and thus plumage color, during molt. Specifically, I predicted 
that jays in better nutritional condition, with greater mass either during the nestling period or during molt, would grow feathers with greater UV chroma. Group dynamics were expected to have a considerable effect on feather color - however, depending on sampling stage, the direction of those effects could differ, i.e. helpers could increase provisioning during the nestling and post-fledgling periods, but those additional birds could be competitors for food after nutritional independence. Because considerable amount of variation in juvenile brightness and chroma can be explained by maternal effects (Tringali et al. 2015), I expected that mother ID would explain a significant proportion of the variation in feather UV color. Similarly, I expected that juvenile color would be correlated with adult color. However, I predicted jays living in territories with a same-sex step-parent would have reduced UV reflectance since they would receive higher aggression levels, potentially lowering social status and increasing stress levels.

I expected a positive correlation between group size and UV reflectance, but only when there was enough oak scrub (i.e. at least 8 ha) in the territory to sustain the group. In cases where a large group was living in a small territory or in a territory without enough oak scrub, I expected to see a decrease in UV reflectance because of increased competition for food (Mumme et al. 2015). To tease apart the interaction between habitat and social effects, I also included two measures of habitat quality within a territory: TSF and oak scrub. I predicted that jays residing in territories with large areas that had burned within the last 2-9 years or with large areas of oak scrub would have feathers with higher UV reflectance (Breininger and Schmalzer 1990, Breininger et al. 1995).

I predicted that the intensity of parasitic infection, specifically microfilariae and trypanosomes, would be negatively correlated with UV reflectance. Because CORT has negative effects on feather quality (DesRochers et al. 2008), I predicted that birds with experimentally administered doses of CORT during molt would reduce feather UV chroma and shift hues farther from the UV spectrum; however, brightness is not expected to change in response to CORT administration.

Lastly, I tested if feather color influenced whether a bird first acquired breeding space as a twoyear-old. Specifically, I predicted that birds with the greatest UV brightness and chroma would gain 
access to breeding positions earlier than duller individuals because brightness and chroma appear to be linked with dominance in juveniles (Tringali and Bowman 2012). 


\section{METHODS}

\section{Study Site and Juvenile Feather Collection}

Research was conducted at Archbold Biological Station, Highlands County, FL (27.108N, 81.218W), where the color banded population of FSJs has been monitored since 1969 (Woolfenden and Fitzpatrick 1984). As part of the long-term demography study, the FSJ population is censused monthly and all nests are found and monitored throughout the breeding season. All nestlings are banded on day 11, and a blood sample is collected to determine gender. All fledglings that survive are recaptured once they reach nutritional independence at 80-90 days for additional banding, measurements, and blood and

juvenile feather collection after preformative molt. I scanned blood samples to estimate endoparasite abundance (Robbins et al., in prep), and the two outermost rectrices were collected for reflectance measurements. These tail feathers served as the first feather samples for my project (Figure 1). My analyses focused on the annual cohorts from 2013-2015; however, data on change in color metrics and whether color was related to fitness used only the 2013 and 2014 cohorts, since the data necessary for the 2015 cohort will not be collected until later this summer. Subsequent publications will use the full data set for the 2013, 2014, and 2015 cohorts. In total, my sample size included 209 juveniles from these three cohorts, 57 of which survived to adult feather collection for the 2013 and 2014 cohorts. All procedures were conducted under USGS Federal banding permits and Threatened and Endangered Species permits to R. Bowman (07732; TE824723-9), USFWS permits to S. Schoech for CORT dosing (TE117769-7), and IACUC approval through the University of South Florida to R. Windsor (W IS00000947). 


\section{Corticosterone Administration}

In the year following juvenile feather collection, I administered CORT during individuals' first pre-basic molt into adult plumage for each of the 2013-2015 cohorts (Figure 1). I divided all yearlings into three treatment groups: experimental (received CORT doses), sham control (received sham/dummy doses), and control. Jays were randomly assigned to each treatment group, ensuring that siblings within a family group received different treatments and that male:female ratios were relatively even and consistent between treatment groups.

Individuals were dosed with CORT (Sigma Aldrich \#C2505, St. Louis, MO) without capture by provisioning them waxworms that had been injected with a solution of crystalline CORT suspended in peanut oil (Breuner et al. 1998, Schoech et al. 2007). CORT was dissolved in heated peanut oil to a concentration of $0.8 \mathrm{mg} / \mathrm{ml}$, and $25 \mu \mathrm{l}$ was injected into each waxworm with a 100- $\mu 1$ Hamilton syringe, for a CORT dose of $20 \mu \mathrm{g} /$ waxworm. Sham waxworms were injected with $25 \mu \mathrm{l}$ of peanut oil. Waxworms were prepped each morning prior to dosing, and kept on ice to reduce their mobility and prevent oil from seeping out.

I administered CORT-injected or sham-injected waxworms to the selected birds twice a day for three weeks beginning in mid-July when rectrices began growing during molt (Bancroft and Woolfenden 1982). The first dose was administered early in the morning (0630-0900) and the second dose was administered either late morning (0900-1200) or early afternoon (1300-1500) pending on weather or my ability to relocate individuals. This dosing method has been validated in adult FSJs; $20 \mu \mathrm{g}$ doses increase plasma CORT concentrations within 12 minutes, which return back to baseline levels within an hour (Schoech et al. 2007). Thus, I ensured that the second dose was administered no less than two hours after the first dose. FSJs at Archbold Biological Station are relatively tame, and doses were given by locating the target groups, bringing them close by throwing peanuts, and then tossing the appropriate treatment waxworm to the target jay. Most individuals swallowed the waxworm upon receiving it, but I observed those that flew off to ensure they were not caching or provisioning it to fledglings. In these cases, a 
second waxworm dose was provided. Because most of the jays I dosed were helpers, it was not uncommon for individuals to be off foraying, and thus I was not always able to administer two doses to each bird every day.

\section{Blood and Adult Feather Collection}

In the subsequent Jan-Feb (following dosing, but prior to the breeding season), I recaptured surviving individuals for measurements, blood sampling, and adult feather collection. These feathers served as the second samples for each individual, allowing for pair-wise comparisons (Figure 1). Adults were trapped in the winter because structural plumage can be affected by wear, and I wanted to measure UV coloration closest to the time the birds were competing for breeding space.

Individuals were trapped using peanut-baited Potter traps. Blood was collected by veinipuncture of the brachial vein, and I also collected $200-400 \mu 1$ of additional blood (not exceeding $1 \%$ of an individual's body mass) to measure hematocrit and scan for endoparasites. I inspected the plasma of centrifuged capillary tubes under 20-40x magnification to count the number of microfilariae and trypanosomes. Only full cap tubes were scanned for parasites, and each tube was rotated and scanned three times. To minimize the effects of diel fluctuations on parasite levels (Boughton et al. 1938), birds were trapped at 0700-1100. All blood samples were kept on ice until they could be centrifuged and processed in the lab.

\section{Environmental Parameters}

In addition to environmental explanatory variables, I included sex as a categorical variable in models of color as well as juvenile color in models of adult color. 


\section{Nutritional Condition}

I chose to include mass and hematocrit as the main measures of nutritional condition for this study. I compared the effects of several measures of mass for each color variable, but only chose the one with the highest correlation for final models of color. Juvenile and adult masses were measured at the respective times of capture and I also looked at the effects of standardized nestling (age day 11) masses, which were either standardized by average nestling mass per year or per brood. Hematocrit, the proportion of red blood cells to total volume of blood, was measured once blood samples had been centrifuged.

\section{Social Environment}

Social variables included family group size, mother ID, and presence of a same-sex step-parent. Group size was based on census data collected during June and July, when most juveniles are growing their rectrices during preformative molt. Mother ID was included as a random categorical variable. Presence of a same-sex step-parent was determined on a case-by-case basis, and was based on census data collected during July and August, when most adults are growing their rectrices during first pre-basic molt.

\section{Parasites}

I scanned centrifuged capillary tubes for endoparasites, and focused on the two primary bloodborne parasites in FSJs: microfilariae nematodes and trypanosomes (Robbins et al. in prep, Kinsella 1974). Parasite density (per $100 \mu \mathrm{l}$ ) was averaged across multiple capillary tubes per individual. However, due to the abundance of individuals clear of parasite infection, I chose to categorize microfilariae and trypanosome infection into two groups: infected and non-infected.

\section{Habitat Quality}

I included two measures of habitat quality in my analyses: area of oak scrub within each territory and area of habitat last burned between 2-9 years. I compared habitat quality based on TSF and oak scrub using Archbold's GIS grid cell system. Vegetation class distributions (Abrahamson et al. 1984) were 
mapped at Archbold in 2003 and TSF is mapped yearly. FSJ territories also are mapped yearly during the breeding seasons using playbacks and behavioral observations, and I overlaid the territory delineations with vegetation and TSF shapefiles in ArcGIS (ESRI, Redlands, CA) to calculate habitat quality per territory, per year.

Stress

I assessed the effects of stress on plumage color by including treatment group as a categorical variable. To compare differences in color between treatment groups, I used generalized linear models (GLM) and ANOVA.

\section{Breeding Observations}

As part of the monthly population censuses and breeding observations conducted for the longterm demography study, changes in the breeding pairs and creation of new territories are monitored. Thus, I noted if any individuals in the 2013-2015 yearly cohorts acquired a breeder position (Figure 1). Birds that acquired a breeder position were considered breeders for the study, despite whether they produced eggs that same year. Individuals that did not acquire breeding space were listed as helpers or denoted as missing. Breeding statuses were recorded at the end of May since few individuals acquire breeding space after this point in the breeding season.

\section{Spectroscopy}

I quantified UV reflectance of the two outermost rectrices with an Ocean Optics FLAME-S Spectrometer, a DH-2000 deuterium halogen light source, and a bifurcated fiber optic probe (Ocean Optics, Dunedin, FL) (Montgomerie 2006). Following previous reflectance measurement protocols on FSJs (Siefferman et al. 2008, Tringali and Bowman 2012), I used a rubber mount fastened to the probe to 
maintain a $90^{\circ}$ measuring angle to the feather at a distance of $0.5 \mathrm{~cm}$. This ensured a consistent lit area of $3.14 \mathrm{~mm}^{2}$ for measurements. I measured and averaged reflectance spectra at three points on each feather: 1,2 , and $3 \mathrm{~cm}$ from the distal end.

I used Montgomerie's (2008) CLR program to calculate brightness, chroma, and hue. Mean brightness is the percent of light reflected off the feather between 300 and $700 \mathrm{~nm}$. UV chroma is the ratio of reflectance in the UV range to the total reflectance of the feather. Hue is the wavelength (nm) of peak reflectance between 300 and $700 \mathrm{~nm}$.

\section{Statistical Analysis}

I used R ver. 3.2.5 (R Development Core Team 2016) for all analyses and graphs. I used Pearson's product-moment correlations to test for correlations among the three color variables. To examine consistency of color, I calculated relative change in color within individuals and used paired ttests to determine if juvenile color was significantly different than adult color. I compared relative change in color between males and females using paired t-tests. I also used Pearson's correlations to determine if juvenile and adult color were correlated.

I used generalized linear mixed models (GLMM) to examine the effects of social environment, habitat quality, nutritional condition, parasites, and stress on juvenile color, adult color, and relative change in color. All variables were scaled and centered prior to inclusion in models. Mixed models were only used when Mother ID was included as a random variable; GLMs were used when Mother ID was excluded. I used a variety of methods to investigate the effects of each environmental parameter on the color variables: individual correlations with each explanatory parameter, step-wise selection, and $\Delta$ AIC. I also tested the effect of several interaction terms, but only included one significant effect in my final models, Group Size * Area of Scrub. The environmental variables that had the highest correlations with color and were selected by multiple methods were then included in one top model for each color variable. 
I estimated $\mathrm{R}^{2}$ values for the GLM(M)s using the 'piecewiseSEM' package in R (Lefcheck 2016) according to Nakagawa and Schielzeth (2013).

Because of occasional difficulty acquiring field samples, I found that $11 \%$ of the juvenile data and $3.5 \%$ of the adult data were missing select values in parasite counts, hematocrit, area of oak scrub, or area of desirable TSF. To account for these missing values, I used multiple imputation to estimate missing values, which were calculated using predictive mean matching (van Buuren and Groothuis-Oudshoorn 2011). I followed the recommendations of White et al. (2011) and created a number of iterated data sets that matched the percentage of missing values. Models of color were run over each of the imputed data sets, and the results from each were then pooled and averaged.

I used GLMs (binomial distribution, logit link function) to test if adult color or the relative change in color predicted breeding fate (breeders vs. helpers) for males and females separately. While I excluded missing birds $(\mathrm{n}=6)$ from these analyses, I also ran multinomial models with missing birds included to determine if their exclusion biased results. 


\section{RESULTS}

\section{Tri-stimulus Color Measures}

My three measures of color, brightness, chroma, and hue, were significantly correlated (Figure 2). Chroma and hue negatively covaried (Pearson correlation: $r=-0.74, p<0.001, n=209$ ) which is consistent with other studies of structural plumage (Shawkey et al. 2003, Siefferman et al. 2008); however, in contrast with these studies, I found that brightness negatively covaried with chroma $(\mathrm{r}=-$ $0.20, \mathrm{p}<0.001, \mathrm{n}=209)$ and positively covaried with hue $(\mathrm{r}=0.19, \mathrm{p}=0.005, \mathrm{n}=209)$. Variation was greatest in brightness (Coefficient of Variation: female $=7.33$, male $=8.65$ ) and lowest in chroma (female $=3.09$, male $=3.07$ ). As with other studies of FSJ structural color (Siefferman et al. 2008, Tringali and Bowman 2012), I chose to examine color measures individually rather than with a PCA because of differences in their physical properties (Shawkey et al. 2003) and signaling functions (Bridge et al. 2007).

Both male and female FSJs reflected the most light in the UV-blue area of the spectrum, and their hues did not differ significantly as juveniles ( $\mathrm{t}$-test: $\left.\mathrm{t}_{204}=-1.34, \mathrm{p}=0.18\right)$ nor adults $\left(\mathrm{t}_{53}=-0.68, \mathrm{p}=0.50\right.$; Table 1). Females were brighter and reflected significantly more light than males at both ages (juvenile: $\mathrm{t}_{205}=-4.39, \mathrm{p}<0.001 ;$ adult: $\left.\mathrm{t}_{53}=-3.38, \mathrm{p}=0.001\right)$, but males reflected a significantly greater proportion of UV light than females (juvenile: $\mathrm{t}_{206}=2.11, \mathrm{p}=0.04$; adult: $\mathrm{t}_{53}=2.42, \mathrm{p}=0.02$; Table 1 ).

\section{Consistency of Color}

I recaptured 57 out of 61 surviving individuals for adult feather collection for the 2013 and 2014 cohorts, and survival was equal between males $(n=28)$ and females $(n=29)$. Within individuals, juvenile color was significantly different than adult color for all three color variables: adult feathers were 
significantly less bright than juvenile feathers (paired t-test: $t_{56}=5.02, \mathrm{p}<0.001$ ), with a greater proportion of light in the UV range $\left(\mathrm{t}_{56}=-4.40, \mathrm{p}<0.001\right)$ and a significant shift toward shorter hues $\left(\mathrm{t}_{56}=3.29\right.$, $\mathrm{p}=0.002$ ). Individuals experienced a $4.20 \pm 6.56 \%$ reduction in brightness, a $2.07 \pm 3.47 \%$ increase in chroma, and a $3.87 \pm 10.09 \%$ reduction in hue in their adult feathers relative to their juvenile feathers (Figure 3). Relative change between juvenile and adult feathers was consistent for males and females in brightness (paired t-test: $\left.\mathrm{t}_{54}=-1.81, \mathrm{p}=0.08\right)$, chroma $\left(\mathrm{t}_{52}=0.94, \mathrm{p}=0.35\right)$, and hue $\left(\mathrm{t}_{52}=-0.91, \mathrm{p}=0.37\right.$; Figure 4).

Juvenile and adult color also were highly correlated within individuals (Figure 5). I found a significant positive correlation between juvenile and adult color in brightness $(r=0.60, p<0.001, n=57)$ and chroma $(\mathrm{r}=0.33, \mathrm{p}=0.01, \mathrm{n}=57)$, but not in hue $(\mathrm{r}=0.10, \mathrm{p}=0.45, \mathrm{n}=57)$. The brightest juveniles that reflected the largest proportions of UV light were also the brightest adults with the highest proportions of UV chroma. However, this relationship was not consistent across all individuals in the population. While individuals appeared to remain in the same relative color position within the population, the brightest individuals experienced reductions in color as adults while the duller individuals experienced increases in their color. These correlations did not differ between males and females (Figure 6).

\section{Effects of Environmental Conditions}

\section{Juvenile Plumage Color}

Variation in juvenile plumage reflectance was best explained by nutritional condition, social aspects, and habitat quality. Brightness was significantly correlated with sex and microfilariae infection, and correlations with area of desirable TSF (2-9 years) and trypanosome infection approached significance (Table A1). Based on individual regressions, stepwise selection, and comparisons by $\triangle \mathrm{AIC}, \mathrm{I}$ assembled a final LMM for juvenile rectrix brightness that included sex, juvenile mass, mother ID, hematocrit, area of TSF 2-9 years, as well as microfilariae and trypanosome infection. All of the listed 
variables were significant predictors of juvenile brightness except trypanosome infection, which approached significance (Table 2). Females were brighter than males, and brighter juveniles were also larger, with a greater proportion of red blood cells and clear of blood parasite infection. Brighter juveniles also tended to reside in territories with smaller areas of desirable TSF (2-9 yrs). Mother ID was included as a random effect, and explained $13 \%$ of the total $34 \%$ of observed variation in juvenile brightness (Table 2).

I repeated the same analysis of potential predictors for juvenile chroma using individual regressions (Table $\mathrm{A} 2$ ), stepwise selection, and $\triangle \mathrm{AIC}$, and identified six significant predictors: sex, standardized day 11 mass by year, mother ID, hematocrit, and an interaction between group size and area of oak scrub. Standardized day 11 mass by brood also was a significant predictor of juvenile chroma, but mass standardized by year explained more variation in chroma and was selected for the final model. All of these variables were significant predictors of juvenile chroma, except group size and area of oak scrub; however, the interaction between these terms was a strong predictor of chroma (Table 3). Juvenile males reflected a greater proportion of UV light than females, and individuals with greater chroma had fewer red blood cells and weighed less at day 11 than other juveniles measured that year. Birds that reflected a greater proportion of UV chroma also tended to reside in territories with larger family groups and smaller areas of oak scrub, with a distinct significant interactive effect between these two variables on juvenile chroma. Mother ID was a strong predictor of juvenile chroma, and explained $37 \%$ of the total $47 \%$ variation explained by the model (Table 3).

Variation in juvenile hue was predicted by variables very similar to those of juvenile chroma (Table A3), likely due to the strong negative correlation between these two variables (Figure 2). I found four significant predictors of juvenile hue that appeared in several of my predictor assessments: sex, standardized day 11 mass by year, mother ID, group size, and area of oak scrub. All of these variables were significant predictors of juvenile hue when combined in one LMM, except area of oak scrub (Table 4). Juvenile males reflected the most light at shorter wavelengths, closer to the UV spectrum, than 
juvenile females. Individuals whose peak reflectance was at shorter wavelengths, closer to the UV spectrum, were smaller as nestlings when compared to other nestlings born that year. Additionally, birds with peak reflectance at shorter wavelengths tended to reside in territories with larger family groups and larger areas of oak scrub. Similar to juvenile chroma, the effects of group size and area of oak scrub were likely intensified due to a significant interactive effect. As with other juvenile measures of plumage color, mother ID was a strong predictor of hue, and explained $20 \%$ of the total $39 \%$ variation explained by the model (Table 4).

\section{Adult Plumage Color}

Survival from juvenile feather collection to adult feather collection was equal between the sexes (males=26, females=25). I maintained the same explanatory environmental parameters in the models of adult color, but I added corticosterone treatment group as an additional parameter and compared adult mass to day 11 nestling standardized masses. Regression, step-wise selection, and comparison with $\Delta$ AIC showed that several nutritional, habitat quality, and stress variables affected adult plumage color. I identified six variables that explained 56\% of the variation in adult brightness: sex, juvenile brightness, adult mass, microfilariae infection, group size, and area of oak scrub (Table 5). Despite explaining 32\% of the observed variation in adult brightness, mother ID was not included in the model because it increased $\Delta$ AIC compared to the null model (Table A4). Presence of a same-sex step-parent did not affect any adult feather color variables (Tables A4-A6). Juvenile brightness explained a large proportion of variation in adult brightness; brighter juveniles were also the brighter adults. Adult females were brighter than adult males, and brighter individuals were smaller and infected by microfilariae. However, the effect of microfilariae is likely biased by one outlying individual, who had an unusually high infection of 34 microfilariae/100 $\mu 1$. Brighter adults also tended to reside in territories with larger family groups and larger areas of oak scrub. A significant interactive effect exists between these two variables on adult brightness, where less bright individuals likely inhabited territories with less oak scrub and larger families (Table 5). There was little effect of CORT on adult brightness (Figure 7, Table A4). 
I repeated my parameter analyses for adult chroma, and Mother ID explained considerably less variation than in juvenile chroma, and was not included in the model of adult chroma (Table A5). Individual regressions of each parameter with adult chroma are presented in Table A5. Nestling mass standardized by year was not a significant predictor of adult chroma as it was for juvenile chroma; however, mass standardized by brood was significant, and included in the models. Adult chroma was best explained by juvenile chroma, sex, standardized day 11 mass by brood, group size, area of oak scrub, trypanosome infection, and CORT treatment (Table 6). These variables explained $46 \%$ of the observed variation in adult chroma. Adult males reflected a larger proportion of UV light than females, and adult chroma was significantly positively correlated with juvenile chroma. Adults with higher proportions of UV chroma also were larger as nestlings compared to other nestlings within their brood, and infected with trypanosomes. These individuals also tended to inhabit territories with larger family groups and larger areas of oak scrub, with a significant interactive effect between these two variables on adult chroma. Lastly, CORT had a significant effect on adult chroma; individuals dosed with CORT during molt had lower proportions of UV chroma compared to control and sham control individuals (Figure 7, Table 6).

As observed with juvenile hue, adult hue was predicted by similar variables to adult chroma, likely due to the negative correlation between these two color variables (Figure 2). Mother ID explained little of the variation in adult hue, and was not included in the final model (Table A6). Individual regressions of each parameter with adult hue are presented in Table A6. Adult hue was best explained by sex, juvenile hue, standardized day 11 mass by brood, group size, area of oak scrub, and CORT treatment (Table 7). As I observed with juveniles, adult males had peak reflectance at shorter wavelengths, and were closer to the UV spectrum than adult females. Individuals with peak reflectance at shorter wavelengths also were larger as nestlings compared to their brood mates, and tended to reside in territories with larger groups and larger areas of oak scrub. There also was a significant, positive interactive effect on adult hue. CORT had a considerable effect on adult hue, where individuals dosed 
with CORT had peak reflectance at longer wavelengths than control and sham control birds (Figure 7, Table 6). These variables explained $24 \%$ of the variation observed in adult hue.

\section{Relative Change in Plumage Color}

In addition to juvenile and adult color, I repeated parameter comparisons and selection for relative change in color, and identified the top contributing environmental variables to change in color (Table A7). Change in color ranged considerably (-24.3 - $22.0 \%$ change) across brightness, chroma, and hue, and top models of relative change explained only a quarter of the observed variation. I found five variables that affected change in FSJ rectrix brightness: sex, juvenile mass, microfilariae infection, group size, and area of oak scrub (Table 8). Males experienced greater reductions in brightness compared to females, and similarly, larger birds had greater reductions in brightness than smaller birds. Individuals clear of microfilariae infection showed greater reductions in brightness than infected individuals. Group size had a negative effect on change in color, whereas area of scrub had a positive effect on color change; individuals tended to exhibit greater reductions in color when living in territories with big family groups and small areas of oak scrub. I also noted a significant negative interactive effect between group size and area of oak scrub on change in brightness ( $\mathrm{p}=0.03$, Table 8$)$. Change in brightness was affected by similar environmental variables to adult brightness, but microfilariae infection was not a strong predictor (Table A7).

Examining individual parameter regressions, relative change in chroma across molts was only significantly correlated with standardized mass by brood (Table A8). Stepwise selection also identified trypanosome infection as a potential predictor of change in chroma, so I included both of these variables in my model (Table 9). When combined in one model, both standardized mass (brood) and trypanosome infection were significant predictors of relative change in chroma, and explained $24 \%$ of the observed variation. Individuals who were smaller than their brood mates at day 11 experienced larger reductions in chroma as adults. Birds that were infected with trypanosomes showed greater reductions in chroma compared to individuals that were free of infection. Despite their prevalence in models of adult chroma, 
sex, CORT treatment, group size, and area of oak scrub were not strong predictors of relative change in chroma (Table A8).

I identified three environmental variables that explained $23 \%$ of the observed variation in relative change in hue: standardized mass by brood, CORT treatment, and trypanosome infection (Table 10). Individuals that were larger than their brood mates at age day 11 experienced greater shifts toward shorter wavelengths, closer to the UV spectrum, as adults than their smaller siblings. As I saw with adult hue, CORT influenced change in hue. Birds that received doses of CORT showed very little relative change in their hue across molts, whereas control and sham control birds both showed shifts toward shorter wavelengths as adults. Interestingly, birds that were infected by trypanosomes also experienced greater shifts toward shorter wavelengths compared to birds clear of infection. Despite their importance as predictors of adult hue, I did not see significant effects of sex, group size, and area of oak scrub on relative change in hue (Table A9).

Effects of corticosterone. Because of the significant effects of CORT administration on adult plumage coloration, I further explored differences among the three CORT treatment groups by examining relative change in color. CORT administration appeared to affect both sexes equally, however notable differences existed between males and females in the sham control group (Figure 8). When controlling for sex, no significant differences existed between treatment groups for any of the color variables, although chroma in females approached significance $\left(\mathrm{t}_{\text {experimental }}=-2.00, \mathrm{p}=0.056, X^{2}=4.02\right)$. Males and females dosed with CORT had lower proportions of UV chroma and hues shifted to longer wavelengths than control and sham control birds. Brightness was not different among treatment groups. Despite the observed differences in adult color, I did not find a significant difference in relative change in color among treatment groups (Figure 9). This is likely due to the variation in change within the population, where birds with greater reflectance experienced reductions in color and less reflective birds experienced increases in color (Figure 10). Regression slopes are similar for all three treatment groups for adult brightness, but correlations for chroma and hue differed across treatment groups. While individuals were 
more scattered in chroma and hue, notably in the control group, experimental group birds had a reduced slope compared to sham control birds (Figure 10). Birds dosed with CORT experienced greater changes, both increases and decreases, in their chroma and hue than control and sham birds.

\section{Effects of Color on Reproduction}

I monitored breeding fate for 51 out of the 57 adults that I recaptured for feather collection. Six individuals disappeared from the study population before the May cut-off, and these individuals were removed from binomial GLMs of breeding fate. To ensure that the removal of these individuals did not bias my analyses, I ran multinomial tests of color on breeding fate, and found findings consistent to the binomial GLMs. A greater number of both males and females acquired breeding space (males=16, females $=15$ ) than remained as helpers (males $=10$ females $=10)$.

Acquisition of breeding space was not significantly predicted by adult brightness, chroma, nor hue (Table 11, Figure 11). I observed distinct differences in color between males and females, but both sexes had very similar colors as breeders and helpers. While not significant, juvenile color for these individuals was slightly different between breeders and helpers (Table 12, Figure 12). As juveniles, breeder females tended to be brighter with a greater proportion of UV chroma compared to helpers. Both juvenile chroma and hue were marginally significant as predictors of breeding fate in males

$\left(X_{\text {chroma }}^{2}=2.77, \mathrm{p}=0.09 ; X_{\text {hue }}^{2}=3.62, \mathrm{p}=0.06\right)$, but brightness was not a significant predictor. Males that acquired breeding space had a lower proportion of UV chroma and peak reflectance at shorter wavelengths as one-year-olds than helpers. While not significant, breeder males also tended to be brighter than helpers as one-year-olds.

Breeding fate was not significantly predicted by change in brightness, chroma, nor hue for males (Table 13, Figure 13). Both breeder and helper males experienced similar changes in color for all three variables. Breeding space acquisition for females was significantly predicted by both change in brightness 
(GLM: $\left.Z=2.00, X^{2}=5.35, \mathrm{p}=0.02\right)$ and hue $\left(Z=1.92, X^{2}=5.19, \mathrm{p}=0.02\right)$. Females that became breeders experienced greater reductions in brightness than helper females, which showed very little relative change. Breeder females also tended to have hues shifted toward shorter UV wavelengths compared to helpers. 


\section{DISCUSSION}

My UV reflectance correlations between the tri-stimulus variables were not entirely consistent with those measured on FSJs by Siefferman et al. (2008). While I found a consistent negative correlation between chroma and hue, I observed contrary correlations between brightness and chroma, as well as brightness and hue (Figure 2). I adopted the methodology used by Siefferman et al. (2008), but the reflectance curves contained a greater degree of noise and showed higher reflectance in the longer wavelengths compared to other studies of FSJ UV color (Bridge et al. 2007, Tringali and Bowman 2012). My measures of hue also were considerably greater on average than those reported by Siefferman et al. (2008). However, the strong negative correlation between chroma and hue validated my methodology, and I ensured that relative differences between individuals were consistent across varying spectrometer settings.

\section{Consistency of Color}

I found evidence that feather UV coloration changes across yearly molts in FSJs, which is consistent with my initial hypothesis that UV plumage color is a plastic trait. Juvenile plumage was significantly different from adult plumage within individuals (Figure 3), and changes within individuals were consistent for both males and females (Figure 4). Although correlated with juvenile color, individuals were significantly less bright as adults, with greater proportions of UV chroma and peak reflectance at shorter hues, shifted closer to the UV spectrum. My results are contrary to those of Hegyi et al. (2015), who found strong stability of multiple plumage traits in Great Tits across seasons and years; however, it is important to note that my study compared juvenile and adult plumage whereas Hegyi et al. (2015) averaged across ages, including yearlings, when they observed similar color structure across ages. 
For most avian species, adults are more highly ornamented with higher quality plumage than juveniles (Prum 2006, Gill 2007), and my findings are consistent with these general trends. Within individuals, adult feathers reflected significantly greater proportions of UV light than juvenile feathers, and peak reflectance was at significantly shorter wavelengths (Table 1). UV chroma is positively correlated with the number of circular keratin rods within the spongy medullary layer in Eastern Bluebird feather barbs (Shawkey et al. 2003), and thus, adult FSJs with greater UV chroma likely had more keratin rods in their feather barbs. To my knowledge, no tests have been conducted of feather barb strength in relation to keratin rod abundance; however, melanized feather barbs have a higher breaking force than non-melanized barbs (Butler and Johnson 2004), and I hypothesize that the adult feathers with greater numbers of keratin rods would be stronger, with higher breaking force, than juvenile feathers.

Contrary to my predictions, juvenile plumage was brighter, reflecting more light, than adult plumage. Unlike chroma and hue, brightness is not explained by feather barb nanostructure (Shawkey et al. 2003), suggesting that other feather structures, such as thickness of the spongy layer (Andersson 1999), may contribute to variation in UV reflectance. Brightness acts as an indicator of sex in several monomorphic avian species (Eastern Bluebird: Siefferman and Hill 2005, FSJ: Siefferman et al. 2008, Blue Tit: Peters et al. 2011), and greater understanding of the structural mechanisms that contribute to variation in brightness is needed. I suggest two possible explanations that would clarify my observations of greater brightness in juveniles: bacterial degradation and signal evolution via parental preference. Juveniles could be exposed to more keratinolytic bacteria in the nest or during the post-fledging period or may not be as experienced with preening and plumage maintenance, and both scenarios would result in greater bacterial loads on feathers, thus increasing brightness (Shawkey et al. 2007). In contrast, UV reflectance in fledglings may have evolved as a signal in response to parental preference (Tanner and Richner 2008). Great Tit nestlings treated with UV blockers were fed less frequently than control nestlings, thus selection may favor bright fledglings if it attracts more attention from provisioning parents. 
Adult and juvenile FSJs are sexually dimorphic in the UV spectrum, where males have lower brightness but higher UV chroma than females (Bridge et al. 2007, Tringali and Bowman 2012), and my results are consistent with these trends (Table 1). Bridge et al. (2007) noted a greater frequency of differences in UV brightness and hue when comparing adults and juveniles than when comparing males and females, and they found no significant differences in brightness between sexes. This would suggest that stronger selective pressure exists on plumage to signal age rather than sex. However, my findings contradict these observations, as I found that females were significantly brighter than males and juveniles were significantly brighter than adults (Table 1). I propose that UV color indicates age and sex, both of which are important factors in dominance. In FSJ dominance hierarchies, males always dominate females, and older birds dominate younger birds (Woolfenden and Fitzpatrick 1977). Furthermore, experimental reduction in UV rectrix chroma resulted in a decrease in dominance in both male and female juveniles (Tringali and Bowman 2012), but no measure of UV color predicted dominance. Thus, plumage reflectance may indicate sex and age, which are important predictors of dominance, but may not act as a signal of dominance itself.

Despite significant differences in reflectance between juvenile and adult plumage, I found strong correlations between juvenile and adult color, where the brightest juveniles with the greatest UV chroma also were the brightest adults with the greatest chroma (Figure 5). Individuals tend occupy the same territory for the first few years of life, where environmental conditions are often the same. However, since birds begin competing for breeding space during their second year, early-life conditions could have longlasting fitness effects on individuals. For example, young that were raised in high quality habitats (van de Pol et al. 2006, Wilkin and Sheldon 2009), with more nest helpers (Brouwer et al. 2012), or that were larger than their brood mates (Tilgar et al. 2010), had higher survival and breeding success. In FSJs, nestling body mass is positively associated with post-fledgling survival (Mumme et al. 2015); thus, natal conditions that influenced juvenile feather color could have carry over effects that also influence adult feather color and potentially reproductive fitness. 


\section{Effects of Environmental Conditions}

\section{Juvenile vs. Adult Color}

Variation in FSJ feather reflectance was explained by several environmental variables, however, the tri-stimulus variables were affected differently. Juvenile brightness was influenced by juvenile mass, hematocrit, area of habitat in the optimum TSF range, and both trypanosome and microfilariae infection. In contrast, juvenile chroma and hue were influenced by standardized nestling mass (year), hematocrit, and an interaction between group size and area of oak scrub (Tables 2-4). While all three reflectance measures were predicted by hematocrit, I find it noteworthy that brightness was affected by parasite infection and juvenile mass, which are specific to each individual, whereas chroma and hue were affected by standardized nestling mass, group size, and area of oak scrub, which in some cases are shared among brood mates. If brightness is dependent on width of the spongy layer (Andersson 1999) and chroma and hue are dependent on the number of keratin rods within the spongy layer (Shawkey et al. 2003), then perhaps different aspects of feather growth are affected by different sets of environmental conditions. I also found a strong influence of maternal effects on juvenile brightness, chroma, and hue, supporting the hypothesis of FSJ feather reflectance heritability (Tringali et al. 2015) either through inheritance from the female breeder or behavioral differences between female breeders. Juvenile FSJs are still dependent on their families for food and defense from predators while they are growing their rectrices, thus their feather color likely reflects natal environmental conditions.

Interestingly, maternal effects were not strong predictors of adult feather color like juvenile color was, and I propose that genetic or parental effects are small or short-lasting relative to natal environmental effects. When adults begin pre-basic molt, they are nutritionally independent from their families, and environmental conditions may have a greater effect on feather growth and color. Adult brightness was predicted by adult mass, microfilariae infection, and an interaction between group size and area of oak scrub, whereas variation in chroma and hue were explained by standardized nestling mass (brood), an interaction between group size and area of oak scrub, and treatment with CORT (Tables 5-7). 
I found no support for my hypothesis that presence of a same-sex step-parent would reduce feather color due to increased aggression levels, and perhaps any effects are not strong enough to affect color.

Hematocrit was no longer a strong predictor of feather reflectance in adults like it was in juveniles, likely due to a combination of increased erythropoiesis in adult birds (Fair et al. 2007) and the reduced survival of fledglings with low hematocrit. Parasite infection was present in models of adult brightness and chroma, which I found surprising since parasite infections increase with age in FSJs (Robbins et al., in prep). Another notable difference from juvenile color models is the presence of the interaction between group size and area of oak scrub as a predictor of all three tri-stimulus variables. Variation in juvenile brightness was not explained by this interaction like juvenile chroma and hue, and the presence of this interaction between family size and territory habitat quality indicates its continued role in adult FSJ reflectance. Although mother ID did not predict adult reflectance like juvenile reflectance, juvenile color was a strong predictor of adult color for all three color variables.

Despite the age-associated behavioral differences between juveniles and adults, I found that similar environmental variables affected brightness, chroma, and hue, at multiple stages of life. Juvenile and adult brightness were strongly affected by mass at time of capture and parasite infection, while chroma and hue were affected by standardized nestling mass and the interaction between group size and area of oak scrub. This interaction also was an important variable in models of adult brightness, and I am unsure why the area of desirable TSF was such a strong predictor of juvenile brightness since it was not a strong predictor of any other color variables for juveniles or adults. TSF also was negatively correlated with juvenile brightness, contrary to my hypothesis, which is puzzling since jays depend on fire to maintain habitat structure, and may abandon areas that are too overgrown (Woolfenden and Fitzpatrick 1984). Perhaps TSF indirectly affects feather color through other physiological processes. TSF affects vegetation structure, influencing predation risk, which could affect individual condition through increased stress or more time spent on sentinel, therefore reducing time available for foraging. 
I found the difference in capture vs. standardized mass as predictors interesting, since capture mass was a stronger predictor of brightness and standardized nestling mass explained more of the variation in chroma and hue. While capture mass positively predicted juvenile brightness, it negatively predicted adult brightness, disproving my hypothesis. If brightness is dependent on condition, then I would have expected brighter birds to be larger; however, this correlation was only observed in juveniles, and more research on the mechanisms behind brightness is needed. Standardized mass by year was important in juvenile chroma and hue, and indicated how an individual compared to all other same-age individuals in the population. However, standardized mass by brood, which was a predictor of adult color, indicated how an individual compared to their siblings, with whom they are directly competing. In terms of juvenile feather reflectance, it is important to be larger as a nestling than others in your yearly cohort and the effect this has on coloration continues into adulthood. As an adult, if you were larger than your siblings as a nestling, you are more likely to be have greater chroma and shorter hues. However, the observed correlations between feather color and mass were not consistent among juveniles and adults. I predicted that birds with greater chroma and shorter hues would be larger with more red blood cells, but I found opposite, significant trends for juveniles (Table 3). Perhaps this discrepancy between juvenile condition and feather color results from variation in parental care rather than individual condition, since nestlings are still dependent on their families for food during their preformative molt.

As mentioned previously, there appears to be an interaction between brightness, chroma, and hue acting as a signal for sex, age, and potentially dominance. If brightness is determined by mass at capture, then it may indicate sex or condition since male FSJs are larger than females. However, if chroma and hue, which are inversely correlated (Figure 2), are determined by standardized nestling mass, then they may better indicate relative condition or position within the dominance hierarchy.

\section{Relative Change in Reflectance}

I observed considerable changes in feather reflectance between juvenile and adult plumages, but models of relative change in color were not entirely consistent with models of juvenile and adult color. 
Change in brightness was predicted by variables that appeared in models of juvenile and adult brightness, and included juvenile mass, microfilariae infection, group size, and area of oak scrub (Table 8). Change in chroma, however, was only predicted by standardized mass (brood) and trypanosome infection, and did not include the other significant predictors of adult chroma: group size, area of oak scrub, and CORT treatment (Table 9). Since I found similar models for juvenile and adult chroma, I was surprised that those same models did not predict relative change in chroma. Relative change in hue was predicted by standardized nestling mass (brood), CORT treatment, and interestingly, trypanosome infection, which was not a strong predictor of juvenile nor adult hue (Table 10). However, since trypanosome infection was a strong predictor of adult chroma, and chroma and hue are negatively correlated, perhaps this manifested in the models of change in hue as well. My models of relative change in color did not explain as much of the observed variation in color as models of juvenile and adult color, so it seems that change in color is affected by other variables or conditions that I did not include in my study.

\section{Effects of Corticosterone}

Individuals that experienced increased instances of stress during molt grew feathers with considerably lower proportions of UV chroma and longer hues (Figure 8), supporting my hypothesis. UV chroma is positively correlated with the number of keratin rods within feather barbs (Shawkey et al. 2003), and since CORT inhibits protein deposition (Sapolsky et al. 2000, Romero et al. 2005), resulting in lighter, weaker feathers (DesRochers et al. 2008, Lattin et al. 2011), then the altered feather barb nanostructure likely reduced the amount of UV chroma. Individuals that received doses of CORT also tended to have brighter feathers compared to control and sham individuals (Figures 7, 8). However, as I found with models of relative change in color, CORT treatment did not have a large effect on relative change in brightness, chroma, nor hue (Figure 9). Individuals dosed with CORT experienced both greater increases and decreases in their chroma and hue than control and sham control birds (Figure 10), which

could have concealed any potential trends. The range in color change in response to CORT administration also suggests that other factors are likely interacting with the way an individual responds to stress and 
regulates the added hormone. If CORT is negatively correlated with body mass in FSJs (Schoech et al. 1997), then condition may interact with CORT levels and CORT response, and could have considerable consequences on feather reflectance.

\section{Effects of Color on Reproduction}

Sexual selection does not appear to have a role in UV reflectance for adult FSJs. Contrary to my prediction, no measure of adult rectrix reflectance significantly predicted acquisition of breeding space (Table 11). Juvenile color also was not a significant predictor of acquisition of breeding space (Table 12, Figure 12). Since UV reflectance is associated with dominance in juveniles (Tringali and Bowman 2012), I had predicted that the brighter individuals with greater proportions of chroma would gain access to breeding positions over more dull individuals, but contrary to prediction, breeders and helpers had similar measures of brightness, chroma, and hue when separated by sex (Figure 11). Since UV brightness is correlated with reproductive fitness in other avian species (Hill 1988, Avilés et al. 2008), I acknowledge that my measure of fitness, acquisition of breeding space, may not be as accurate as other measures of reproductive fitness, such as total number of fledglings produced. However, since FSJs are a long-lived species and lifetime reproductive fitness is correlated with age at first breeding (Woolfenden and Fitzpatrick 1984), I feel that acquisition of breeding space was appropriate for the scope of this project and feasible given my research time frame.

Relative change in UV color across molts was a significant predictor of breeding space acquisition, but only in females (Table 13). Females that obtained breeding space had greater reductions in brightness and shifts toward shorter wavelengths than helper females, who experienced very little relative change across molts (Figure 13). While the physiological mechanism of brightness is still unknown, if brightness is linked with condition (Andersson 1999), then females who gained access to breeding space should have been in poorer condition, with less energy, when they were molting their 
adult feathers compared to when they were juveniles. This seems contradictory since I assume the best individuals are the first to obtain breeding spaces. During late summer, coinciding with the first pre-basic molt, and then again in January - March immediately preceding the breeding season, non-breeders make frequent forays away from their natal territory (Woolfenden and Fitzpatrick 1984, Clayton and Emery 2007), presumably searching for potential breeding opportunities and assessing the competitive pool of other non-breeders. Females that make more frequent and longer forays may divert energy from molt and produce less bright feathers. The trade-off might be that they have better opportunities to obtain breeding space come the following spring. However, in previous work, chroma was associated with condition in FSJs (Shawkey et al. 2003, Siefferman et al. 2008), but was not a significant predictor of breeding fate. This is puzzling since chroma and hue are correlated and change in hue also was a significant predictor of breeding fate for females. Since adults had greater proportions of UV chroma than juveniles (Table 1), then any reductions in chroma from energy spent on forays may have been masked.

If there is a link between condition and feather reflectance, then I would have expected similar patterns for both males and females, but this was not the case because male breeders and helpers experienced similar changes in reflectance across molt. This may be due to sex-specific dispersal strategies to maximize lifetime reproductive success. FSJ females are more likely to disperse farther distances and breed as soon as possible, whereas males tend to wait for breeding spots to open closer to their natal territories (Woolfenden and Fitzpatrick 1978). Furthermore, females that begin breeding as one- or two-year-olds produce more breeding offspring than females that breed at age three or older; in contrast, males produce less breeding offspring as one-year-olds and have an advantage if they delay their age at first breeding (Tringali and Bowman, in prep). Thus, perhaps females are more likely to expend energy foraying earlier in life than males, resulting in greater reductions in brightness than males. 


\section{Conclusions}

Sexual selection drives the evolution of avian plumage ornamentation for many species, but does not appear to be an important factor in the evolution of FSJ feather UV reflectance. My analyses showed that plumage reflectance is a plastic phenotypic trait that changes across annual molts within individuals, and much of the observed variation in color can be explained by environmental conditions. However, juvenile color is correlated with adult color, likely due to consistent environmental conditions since individuals remain in their natal territories for the first few years. Thus, early-life conditions can have long-lasting impacts on an individual, possibly affecting reproductive fitness since birds begin competing for breeding space during their second year. UV reflectance is correlated with condition in juveniles (Siefferman et al. 2008), and appears to be an honest signal of individual quality in adults as well, reflecting how much energy an individual was able to allocate to feather growth while also trying to forage, compete with conspecifics, hide from predators, and cope with endoparasite infection. Birds react to stressors with the release of CORT (Sapolsky et al. 2000), and frequent spikes of CORT can have detrimental effects on plumage reflectance, as my study demonstrates. However, in order to causally link environmental conditions, such as habitat quality, with plumage reflectance, more research on the relationship between environmental stressors, baseline CORT, and the CORT response is needed.

Although UV color is associated with dominance in juvenile FSJs (Tringali and Bowman 2012), I was surprised that it was not correlated with acquisition of breeding space since dominant individuals often have an advantage over submissives (Tringali and Bowman, in prep). One potential explanation for this inconsistent finding is that while plumage reflectance may act as a signal for individual condition, FSJs may also use behavioral cues when interacting with conspecifics. When plumage reflectance was experimentally reduced in juveniles, Tringali and Bowman (2012) found that individuals suffered a reduction in the number of dominance interactions won; however, UV color was not correlated with dominance in their experiment. I suggest that UV color acts as a signal of sex, age, and nutritional condition in FSJs, but does not explicitly signal dominance. Rather, it is the combination of UV color and 
personality together which likely determines how jays perceive and interact with one another. This may explain why studies of plumage color and dominance have found conflicting results, and more research on the link between plumage color, personality, and dominance is needed.

An alternative explanation for the disconnect between plumage reflectance and reproductive fitness in FSJs is that personality and social networking may play a critical role in the acquisition of breeding space. In Great Tits, personality predicts social network size, where fast-exploring individuals associated with more conspecifics than slow-explorers (Aplin et al. 2013), and this could have profound effects on foraging and breeding success (Oh and Badyaev 2010, Aplin et al. 2012). Furthermore, Oh and Badyaev (2010) found that less ornamented male House Finches (Haemorhous mexicanus) associated with more social groups than highly ornamented finches, suggesting a connection between plumage and social network size. Currently the link between structural color, personality, and social networking is unknown, but future research in this area should consider change in plumage reflectance across molts since that may best indicate energy expenditure during the fall foraying season.

In conclusion, I have shown that plumage UV reflectance is a plastic phenotypic trait in FSJs, associated with habitat quality, family size, stress, and parasite infection. My analyses 1) contribute to the understanding of how environmental sources can affect structural color; 2) support the evidence that early-life conditions can have long-lasting effects on FSJ fitness; 3) shed light on the purpose of structural color as a signal in adult FSJs; 4) provide additional evidence of the effects of increased CORT on feather color in a free-living bird population; and 5) reveal that feather UV reflectance is not the only determining factor of breeding space acquisition. While my study did not find a correlation between plumage color and breeding space acquisition, there is a chance that adult UV reflectance may predict reproductive success on a yearly basis. Since UV color changes across molts and reflects condition, then perhaps it correlates with how much energy an individual can put into reproduction that breeding season. 


\section{REFERENCES}

Abrahamson, W. G. (1984). Species Responses to Fire on the Florida Lake Wales Ridge. American Journal of Botany 71:35-43.

Abrahamson, W. G., A. F. Johnson, J. N. Layne, and P. A. Peroni (1984). Vegetation of the Archbold Biological Station, Florida: An example of the southern Lake Wales ridge. Florida Scientist 47:209250.

Andersson, M. B. (1994). Sexual Selection. In. Princeton University Press, Princeton.

Andersson, M., and Y. Iwasa (1996). Sexual selection. Trends in Ecology \& Evolution 2:53-58.

Andersson, S. (1999). Morphology of UV Reflectance in a Whistling-Thrush: Implications for the Study of Structural Colour Signalling in Birds. Journal of Avian Biology 30:193-204.

Angelier, F., J. C. Wingfield, H. Weimerskirch, and O. Chastel (2010). Hormonal correlates of individual quality in a long-lived bird: a test of the "corticosterone-fitness hypothesis". Biology letters 6:846-9. doi: $10.1098 / \mathrm{rsbl} .2010 .0376$

Aplin, L. M., D. R. Farine, J. Morand-Ferron, E. F. Cole, A. Cockburn, and B. C. Sheldon (2013). Individual personalities predict social behaviour in wild networks of great tits (Parus major). Ecology Letters 16:1365-1372. doi: 10.1111/ele.12181

Aplin, L. M., D. R. Farine, J. Morand-Ferron, and B. C. Sheldon (2012). Social networks predict patch discovery in a wild population of songbirds. Proceedings of the Royal Society of Biology 279:41994205. doi: 10.1098/rspb.2012.1591

Atkinson, C. T., and C. I. van Riper (1991). Pathogenicity and epizootiology of haematozoa: Plasmodium, Leucocytozoon, and Haemoproteus. In Bird-Parasite Interactions (J. E. Loye and M. Zuk, Editors). Oxford University Press, New York, pp. 19-48.

Avilés, J. M., E. Solís, J. Valencia, C. de la Cruz, and G. Sorci (2008). Female and male plumage brightness correlate with nesting failure in azure-winged magpies Cyanopica cyanus. Journal of Avian Biology 39:257-261.

Bancroft, G. T., and G. E. Woolfenden (1982). The molt of scrub jays and blue jays in Florida. Ornithological Monographs 29:1-51.

Bonier, F., P. R. Martin, I. T. Moore, and J. C. Wingfield (2009). Do baseline glucocorticoids predict fitness? Trends in Ecology and Evolution 24:634-642. doi: 10.1016/j.tree.2009.04.013

Bortolotti, G. R., F. Mougeot, J. Martinez-Padilla, L. M. I. Webster, and S. B. Piertney (2009). Physiological stress mediates the honesty of social signals. PloS ONE 4:e4983. doi: 10.1371/journal.pone.0004983

Boughton, D. C., E. E. Byrd, and H. O. Lund (1938). Microfilarial Periodicity in the Crow. The Journal of Parasitology 24:161-165.

Breininger, D. R., V. L. Larson, B. W. Duncan, R. B. Smith, D. M. Oddy, and M. F. Goodchildt (1995). Landscape Patterns of Florida Scrub Jay Habitat Use and Demographic Success. Conservation Biology 9:1442-1453. 
Breininger, D. R., and P. A. Schmalzer (1990). Effects of Fire and Disturbance on Plants and Birds in a Florida Oak/Palmetto Scrub. American Midland Naturalist 123:64-74.

Breuner, C. W., A. L. Greenberg, and J. C. Wingfield (1998). Noninvasive Corticosterone Treatment Rapidly Increases Activity in Gambel's White-Crowned Sparrows (Zonotrichia leucophrys gambelii). General and Comparative Endocrinology 111:386-394. doi: 10.1006/gcen.1998.7128

Bridge, E. S., J. Hylton, M. D. Eaton, L. Gamble, and S. J. Schoech (2007). Cryptic plumage signaling in Aphelocoma Scrub-Jays. Journal of Ornithology 149:123-130.

Brouwer, L., D. S. Richardson, and J. Komdeur (2012). Helpers at the nest improve late-life offspring performance: Evidence from a long-term study and a cross-foster experiment. PLoS ONE 7:16-20. doi: 10.1371/journal.pone.0033167

Brown, J. L. (1969). Territorial Behavior and Population Regulation in Birds: A Review and ReEvaluation. The Wilson Bulletin 81:293-329.

Butler, M., and A. S. Johnson (2004). Are melanized feather barbs stronger? The Journal of Experimental Biology 207:285-293. doi: 10.1242/jeb.00746

van Buuren, S., and K. Groothuis-Oudshoorn (2011). mice: Multivariate Imputation by Chained Equations in R. [Online.] Available at http://www.jstatsoft.org/v45/i03/.

Clayton, N. S., and N. J. Emery (2007). The social life of corvids. Current Biology 17:R652-R656.

Derim-Oglu, E. N., and V. V. Maximov (1994). Small passerines can discriminate ultraviolet surface colours. Vision Research 34:1535-1539. doi: 10.1016/0042-6989(94)90155-4

DesRochers, D. W., J. M. Reed, J. Awerman, J. A. Kluge, J. Wilkinson, L. I. van Griethuijsen, J. Aman, and L. M. Romero (2008). Exogenous and endogenous corticosterone alter feather quality.

Comparative Biochemistry and Physiology. Part A, Molecular \& Integrative Physiology 152:46-52.

Doucet, S. M., and R. Montgomerie (2003). Multiple sexual ornaments in satin bowerbirds: Ultraviolet plumage and bowers signal different aspects of male quality. Behavioral Ecology 14:503-509. doi: 10.1093/beheco/arg035

Doutrelant, C., A. Grégoire, A. Midamegbe, M. Lambrechts, and P. Perret (2012). Female plumage coloration is sensitive to the cost of reproduction. An experiment in blue tits. The Journal of Animal Ecology 81:87-96. doi: 10.1111/j.1365-2656.2011.01889.x

Fair, J., S. Whitaker, and B. Pearson (2007). Sources of variation in haematocrit in birds. Ibis 149:535552. doi: 10.1111/j.1474-919X.2007.00680.x

Fretwell, S. D., and H. L. J. Lucas (1970). On territorial behavior and other factors influencing habitat distribuion in birds. I. Theoretical development. Acta Biotheoretica 19:16-36. doi: 10.1007/BF01601953

Galván, I. (2011). Ultraviolet-blue plumage colouration can be perceived as an indicator of fluctuating asymmetry by Blue Tits (Cyanistes caeruleus). Journal of Ornithology 152:223-230. doi: 10.1007/s10336-010-0568-y

Gill, F. B. (2007). Ornithology. In Ornithology. Third Edit. W.H. Freeman and Company, New York.

Goldstein, J. M., G. E. Woolfenden, and J. P. Hailman (1998). A same-sex stepparent shortens a prebreeder's duration on the natal territory: Tests of two hypotheses in Florida scrub-jays. Behavioral Ecology and Sociobiology 44:15-22. doi: 10.1007/s002650050510 
Grindstaff, J. L., M. B. Lovern, J. L. Burtka, and A. Hallmark-Sharber (2012). Structural coloration signals condition, parental investment, and circulating hormone levels in Eastern bluebirds (Sialia sialis). Journal of Comparative Physiology. A, Neuroethology, Sensory, Neural, and Behavioral Physiology 198:625-37. doi: 10.1007/s00359-012-0735-0

Grubb, T. C. J. (1989). Ptilochronology : Feather Growth Bars as Indicators of Nutritional Status. The Auk 106:314-320.

Grubb, T. C. J. (2006). Ptilochronology. In. Oxford University Press, New York.

Grubb, T. C. J., G. E. Woolfenden, and J. W. Fitzpatrick (1998). Factors affecting nutritional condition of fledgling Florida Scrub-jays: a ptilochronology approach. The Condor 100:753-756.

Hamilton, W. D., and M. Zuk (1982). Heritable true fitness and bright birds: a role for parasites? Science 218:384-7.

Harper, D. G. C. (1999). Feather mites, pectoral muscle condition, wing length and plumage coloration of passerines. Animal Behaviour 58:553-562. doi: 10.1006/anbe.1999.1154

Hegyi, G., M. Laczi, G. Nagy, E. Szász, D. Kötél, and J. Török (2015). Stable correlation structure among multiple plumage colour traits: Can they work as a single signal? Biological Journal of the Linnean Society 114:92-108. doi: 10.1111/bij.12412

Hegyi, G., J. Török, L. Z. Garamszegi, B. Rosivall, E. Szöllo, and R. Hargitai (2007). Dynamics of multiple sexual signals in relation to climatic conditions. Evolutionary Ecology Research 9:905920.

Henderson, L. J., B. J. Heidinger, N. P. Evans, and K. E. Arnold (2013). Ultraviolet crown coloration in female blue tits predicts reproductive success and baseline corticosterone. Behavioral Ecology 24:1299-1305. doi: 10.1093/beheco/art066

Hewitt, E. L., R. Bowman, G. E. Woolfenden, and J. W. Fitzpatrick (2006). Influence of Recruitment Age on Lifetime Reproductive Success of the Cooperatively Breeding Florida Scrub-Jay. In NAOC.

Hill, G. E. (1988). Age, Plumage Brightness, Territory Quality, and Reproductive Success in the BlackHeaded Grosbeak. The Condor 90:379-388.

Hill, G. E. (2000). Energetic constraints on expression of carotenoid based plumage coloration. Journal of Avian Biology 31:559-566.

Hill, G. E. (2006). Environmental Regulation of Ornamental Coloration. In Bird Coloration: Vol. 1 Mechanisms and Measurements (G. E. Hill and K. J. McGraw, Editors). Harvard University Press, Cambridge, Massachusetts, pp. 507-560.

Hill, G. E., S. M. Doucet, and R. Buchholz (2005). The effect of coccidial infection on iridescent plumage coloration in wild turkeys. Animal Behaviour 69:387-394. doi: 10.1016/j.anbehav.2004.03.013

Hill, G. E., and K. J. McGraw (2006). Bird Coloration: Vol. 1 Mechanisms and Measurements. In. Harvard University Press, Cambridge.

Johnsen, A., K. Delhey, S. Andersson, and B. Kempenaers (2003). Plumage colour in nestling blue tits: sexual dichromatism, condition dependence and genetic effects. Proceedings. Biological Sciences / The Royal Society 270:1263-1270. doi: 10.1098/rspb.2003.2375

Keyser, A. J., and G. E. Hill (1999). Condition-dependent variation in the blue-ultraviolet coloration of a structurally based plumage ornament. Proceedings of the Royal Society B: Biological Sciences 266:771. doi: 10.1098/rspb.1999.0704

Kinsella, J. M. (1974). Helminth Fauna of the Florida Scrub Jay: Host and Ecological Relationships. Helminthological Society of Washington 41:127-130. 
Kodric-Brown, A., and J. H. Brown (1984). Truth in Advertising: The Kinds of Traits Favored by Sexual Selection. The American Naturalist 124:309-323.

Korsten, P., O. Vedder, I. Szentirmai, and J. Komdeur (2007). Absence of status signalling by structurally based ultraviolet plumage in wintering blue tits (Cyanistes caeruleus). Behavioral Ecology and Sociobiology 61:1933-1943. doi: 10.1007/s00265-007-0433-z

Lattin, C. R., J. M. Reed, D. W. DesRochers, and L. M. Romero (2011). Elevated corticosterone in feathers correlates with corticosterone-induced decreased feather quality: a validation study. Journal of Avian Biology 42:247-252. doi: 10.1111/j.1600-048X.2010.05310.x

Laucht, S., and J. Dale (2012). Development of Badges of Status in Captive Male House Sparrows (Passer domesticus) in Relation to the Relative Ornamentation of Flock-Mates. Ethology 118:644653. doi: 10.1111/j.1439-0310.2012.02053.x

Leclaire, S., P. Pierret, M. Chatelain, and J. Gasparini (2014). Feather bacterial load affects plumage condition, iridescent color, and investment in preening in pigeons. Behavioral Ecology 25:11921198. doi: 10.1093/beheco/aru109

Lefcheck, J. S. (2016). piecewiseSEM: Piecewise structural equation modeling in R for ecology, evolution, and systematics. [Online.] Available at http://dx.doi.org/10.1111/2041-210X.12512. doi: 10.1111/2041-210X.12512

Lens, L., and H. Eggermont (2008). Fluctuating asymmetry as a putative marker of human-induced stress in avian conservation. Bird Conservation International 18. doi: 10.1017/S0959270908000336

Ludwig, W. (1932). Das Rechts-Links Problem im Tierreich und beim Menschen. In. Springer, Berlin.

McGowan, K. J., and G. E. Woolfenden (1989). A sentinel system in the Florida scrub jay. Animal Behaviour 37:1000-1006. doi: 10.1016/0003-3472(89)90144-9

McGraw, K. J. (2006a). Mechanics of Carotenoid-Based Coloration. In Bird Coloration: Vol. 1 Mechanisms and Measurements (G. E. Hill and K. J. McGraw, Editors). Harvard University Press, Cambridge, pp. 177-242.

McGraw, K. J. (2006b). Mechanics of Melanin-Based Coloration. In Bird Coloration: Vol. 1 Mechanisms and Measurements (G. E. Hill and K. J. McGraw, Editors). Harvard University Press, Cambridge, pp. 243-294.

McGraw, K. J., J. Dale, and E. A. Mackillop (2003). Social environment during molt and the expression of melanin-based plumage pigmentation in male house sparrows (Passer domesticus). Behavioral Ecology and Sociobiology 53:116-122. doi: 10.1007/s00265-002-0558-Z

McGraw, K. J., E. A. Mackillop, J. Dale, and M. E. Hauber (2002). Different colors reveal different information: how nutritional stress affects the expression of melanin- and structurally based ornamental plumage. The Journal of Experimental Biology 205:3747-55.

Møller, A. P. (1997). Developmental Stability and Fitness: A Review. The American Naturalist 149:916932.

Montgomerie, R. (2006). Analyzing Colors. In Bird Coloration: Vol. 1 Mechanisms and Measurements (G. E. Hill and K. J. McGraw, Editors). Harvard University Press, Cambridge, pp. 90-147.

Montgomerie, R. (2008). CLR. [Online.] Available at http://post.queensu.ca/ mont/color/analyze.html.

Mumme, R. L., R. Bowman, M. S. Pruett, and J. W. Fitzpatrick (2015). Natal territory size, group size, and body mass affect lifetime fitness in the cooperatively breeding Florida Scrub-Jay. The Auk 132:634-646. doi: 10.1642/AUK-14-258.1 
Nakagawa, S., and H. Schielzeth (2013). A general and simple method for obtaining R2 from generalized linear mixed-effects models. Methods in Ecology and Evolution 4:133-142. doi: 10.1111/j.2041210x.2012.00261.x

Oh, K. P., and A. V Badyaev (2010). Structure of Social Networks in a Passerine Bird: Consequences for Sexual Selection and the Evolution of Mating Strategies. The American Naturalist 176:E80-E89. doi: $10.1086 / 655216$

Parsons, P. A. (1990). Fluctuating asymmetry: An epigenetic measure of stress. Biological Reviews 65:131-145. doi: 10.1111/j.1469-185X.1990.tb01186.x

Peters, A., R. H. J. M. Kurvers, M. L. Roberts, and K. Delhey (2011). No evidence for general conditiondependence of structural plumage colour in blue tits: an experiment. Journal of Evolutionary Biology 24:976-87. doi: 10.1111/j.1420-9101.2011.02229.x

van de Pol, M., L. W. Bruinzeel, D. Heg, H. P. van der Jeugd, and S. Verhulst (2006). A silver spoon for a golden future: Long-term effects of natal origin on fitness prospects of oystercatchers (Haematopus ostralegus). Journal of Animal Ecology 75:616-626. doi: 10.1111/j.13652656.2006.01079.x

Prum, R. O. (2006). Anatomy, Physics, and Evolution of Structural Colors. In Bird Coloration: Vol. 1 Mechanisms and Measurements (G. E. Hill and K. J. McGraw, Editors). Harvard University Press, Cambridge, pp. 295-353.

R Development Core Team (2016). R: A language and environment for statistical computing. [Online.] Available at https://www.r-project.org/.

Reudink, M. W., A. E. McKellar, K. L. D. Marini, S. L. McArthur, P. P. Marra, and L. M. Ratcliffe (2015). Inter-annual variation in American redstart (Setophaga ruticilla) plumage colour is associated with rainfall and temperature during moult: an 11-year study. Oecologia 178:161-173. doi: 10.1007/s00442-014-3167-4

Robbins, C. B., R. S. Heiss, M. S. Pruett, R. Bowman, and R. K. Boughton (in prep). Occurrence and costs of microfilariae and trypanosome infections in Florida Scrub-Jays.

Roberts, M. L., E. Ras, and a. Peters (2009). Testosterone increases UV reflectance of sexually selected crown plumage in male blue tits. Behavioral Ecology 20:535-541. doi: 10.1093/beheco/arp028

Romero, L. M., and L. Remage-Healey (2000). Daily and seasonal variation in response to stress in captive starlings (Sturnus vulgaris): Corticosterone. General and Comparative Endocrinology 119:52-9. doi: 10.1006/gcen.2000.7491

Romero, L. M., D. Strochlic, and J. C. Wingfield (2005). Corticosterone inhibits feather growth: potential mechanism explaining seasonal down regulation of corticosterone during molt. Comparative Biochemistry and Physiology. Part A, Molecular \& Integrative Physiology 142:65-73.

Sapolsky, R. M., L. M. Romero, and A. U. Munck (2000). How Do Glucocorticoids Influence Stress Responses? Integrating Permissive, Suppressive, Stimulatory, and Preparative Actions. Endocrine Reviews 21:55-89. doi: 10.1210/er.21.1.55

Schoech, S. J., R. Bowman, E. S. Bridge, G. M. Morgan, M. A. Rensel, T. E. Wilcoxen, and R. K. Boughton (2007). Corticosterone administration does not affect timing of breeding in Florida scrubjays (Aphelocoma coerulescens). Hormones and Behavior 52:191-196.

Schoech, S. J., R. Bowman, and S. J. Reynolds (2004). Food supplementation and possible mechanisms underlying early breeding in the Florida Scrub-Jay (Aphelocoma coerulescens). Hormones and Behavior 46:565-573. doi: 10.1016/j.yhbeh.2004.06.005 
Schoech, S. J., R. L. Mumme, and J. C. Wingfield (1997). Corticosterone, reproductive status, and body mass in a cooperative breeder, the Florida scrub-jay (Aphelocoma coerulescens). Physiological Zoology 70:68-73.

Shawkey, M. D., A. M. Estes, L. M. Siefferman, and G. E. Hill (2003). Nanostructure predicts intraspecific variation in ultraviolet-blue plumage colour. Proceedings of the Royal Society B: Biological Sciences 270:1455-60. doi: 10.1098/rspb.2003.2390

Shawkey, M. D., S. R. Pillai, G. E. Hill, L. M. Siefferman, and S. R. Roberts (2007). Bacteria as an Agent for Change in Structural Plumage Color: Correlational and Experimental Evidence. The American Naturalist 169:S112-S121.

Siefferman, L., and G. E. Hill (2005). Evidence for Sexual Selection on Structural Plumage Coloration in Female Eastern Bluebirds (Sialia Sialis). Evolution 59:1819-1828.

Siefferman, L., M. D. Shawkey, R. Bowman, and G. E. Woolfenden (2008). Juvenile coloration of Florida Scrub-Jays (Aphelocoma coerulescens) is sexually dichromatic and correlated with condition. Journal of Ornithology 149:357-363.

Smith, J. A. M., L. R. Reitsma, and P. P. Marra (2010). Moisture as a determinant of habitat quality for a nonbreeding Neotropical migratory songbird. Ecology 91:2874-2882.

Swaddle, J. P. (1997). Within-individual changes in developmental stability affect flight performance. Behavioral Ecology 8:601-604. doi: 10.1093/beheco/8.6.601

Tanner, M., and H. Richner (2008). Ultraviolet reflectance of plumage for parent-offspring communication in the great tit (Parus major). Behavioral Ecology 19:369-373. doi: 10.1093/beheco/arm142

Temeles, E. J. (1994). The role of neighbours in territorial systems: when are they "dear enemies"? Animal Behaviour 47:339-350. doi: 10.1006/anbe.1994.1047

Tilgar, V., R. Mänd, P. Kilgas, and M. Mägi (2010). Long-term consequences of early ontogeny in freeliving Great Tits Parus major. Journal of Ornithology 151:61-68. doi: 10.1007/s10336-009-0426-y

Tringali, A., and R. Bowman (2016). The benefits of juvenile dominance in Florida Scub-Jays. North American Ornithological Conference, Washington D.C.

Tringali, A., and R. Bowman (2012). Plumage reflectance signals dominance in Florida scrub-jay, Aphelocoma coerulescens, juveniles. Animal Behaviour 84:1517-1522.

Tringali, A., R. Bowman, and A. Husby (2015). Selection and inheritance of sexually dimorphic juvenile plumage coloration. Ecology and Evolution 5:5413-5422. doi: 10.1002/ece3.1793

Vickery, P. D., M. L. J. Hunter, and J. V. Wells (1992). Use of a New Reproductive Index to Evaluate Relationship between Habitat Quality and Breeding Success. The Auk 109:697-705.

White, I. R., P. Royston, and A. M. Wood (2011). Multiple imputation using chained equations: Issues and guidance for practice. Statistics in Medicine 30:377-399. doi: 10.1002/sim.4067

Wilkin, T. A., and B. C. Sheldon (2009). Sex Differences in the Persistence of Natal Environmental Effects on Life Histories. Current Biology 19:1998-2002. doi: 10.1016/j.cub.2009.09.065

Witter, M. S., and S. J. Lee (1995). Habitat Structure, Stress and Plumage Development. Proceedings of the Royal Society B: Biological Sciences 261:303-308. doi: 10.1098/rspb.1995.0151

Woolfenden, G. E., and J. W. Fitzpatrick (1977). Dominance in the Florida Scrub Jay. The Condor 79:112.

Woolfenden, G. E., and J. W. Fitzpatrick (1978). The Inheritance of Territory in Group-Breeding Birds. BioScience 28:104-108. doi: 10.2307/1307423 
Woolfenden, G. E., and J. W. Fitzpatrick (1984). The Florida Scrub Jay: Demography of a CooperativeBreeding Bird. In. Princeton University Press, New Jersey.

Woolfenden, G. E., and J. W. Fitzpatrick (1990). Florida Scrub Jays: a synopsis after 18 years of study. In Cooperative Breeding in Birds: Long-term studies of ecology and behavior (P. B. Stacey and W. D. Koenig, Editors). Cambridge University Press, New York, pp. 241-266.

Woolfenden, G. E., and J. W. Fitzpatrick (1996). Florida Scrub-Jay. In The Birds of North America (A. Poole and F. B. Gill, Editors). American Ornithologists' Union and Academy of Natural Sciences of Philadelphia, Philadelphia.

Zahavi, A. (1975). Mate selection —A selection for a handicap. Journal of Theoretical Biology 53:205214.

Zirpoli, J. A., J. M. Black, and P. O. Gabriel (2013). Parasites and plumage in Steller's jays: an experimental field test of the parasite-mediated handicap hypothesis. Ethology Ecology \& Evolution 25:103-116. doi: 10.1080/03949370.2012.742462 


\section{TABLES}

Table 1. Mean ( \pm SD) color measures of juvenile and adult Florida Scrub-Jay rectrices. Juvenile colors represent all captured individuals for the 2013-2015 cohorts; adult colors represent recaptured individuals for the 2013-2014 cohorts.

\begin{tabular}{cccccc}
\hline Age & Sex & $\mathrm{n}$ & Brightness (\%) & Chroma & Hue (nm) \\
\hline Juvenile & Female & 103 & $9.29 \pm 0.68$ & $0.251 \pm 0.008$ & $432.99 \pm 27.89$ \\
Juvenile & Male & 106 & $8.85 \pm 0.77$ & $0.253 \pm 0.008$ & $428.04 \pm 25.46$ \\
Adult & Female & 29 & $9.10 \pm 0.58$ & $0.257 \pm 0.007$ & $415.68 \pm 37.74$ \\
Adult & Male & 28 & $8.54 \pm 0.67$ & $0.262 \pm 0.008$ & $409.60 \pm 29.91$ \\
\hline
\end{tabular}


Table 2. Linear mixed model of the top parameters that explain variation in juvenile Florida Scrub-Jay rectrix brightness. Variables were included based on their individual correlations with juvenile brightness and their performance in a backward stepwise regression. Mother ID was included in the model as a random effect. The model explains a considerable about of variation in juvenile brightness (conditional $\mathrm{R}^{2}$ $=0.34$ ), and significant parameters are indicated with asterisks.

\begin{tabular}{lcccc}
\hline Parameter & Estimate & SE & $t$ & $p$ \\
\hline Intercept & -0.16 & 0.18 & -0.90 & 0.37 \\
Sex & -0.72 & 0.14 & -4.99 & $<0.001^{*}$ \\
Juvenile Mass & 0.26 & 0.07 & 3.48 & $<0.001^{*}$ \\
Hematocrit & 0.15 & 0.06 & 2.46 & $0.01^{*}$ \\
Microfilariae Infection (no) & 0.39 & 0.13 & 3.07 & $0.002^{*}$ \\
Trypanosome Infection (no) & 0.31 & 0.16 & 1.97 & 0.05 \\
Area of TSF 2-9 yrs & -0.25 & 0.07 & -3.47 & $<0.001^{*}$ \\
\hline Mother ID & \multicolumn{2}{c}{ variance $=0.13$} & & \\
\hline
\end{tabular}


Table 3. Linear mixed model of the top parameters that explain variation in juvenile Florida Scrub-Jay rectrix chroma. Variables were included based on their individual correlations with juvenile chroma and their performance in a backward stepwise regression. Mother ID was included in the model as a random effect. The model explains a considerable about of variation in juvenile chroma (conditional $\mathrm{R}^{2}=0.47$ ), and significant parameters are indicated with asterisks.

\begin{tabular}{lcccc}
\hline Parameter & Estimate & SE & $t$ & $p$ \\
\hline Intercept & -0.23 & 0.11 & -2.13 & $0.03^{*}$ \\
Sex & 0.48 & 0.12 & 4.09 & $<0.001^{*}$ \\
Standardized Mass (year) & -0.23 & 0.06 & -3.71 & $<0.001^{*}$ \\
Hematocrit & -0.13 & 0.06 & -2.10 & $0.04^{*}$ \\
Group Size & 0.06 & 0.07 & 0.83 & 0.41 \\
Area of Oak Scrub & -0.06 & 0.08 & -0.70 & 0.49 \\
Group Size * Scrub & -0.17 & 0.07 & -2.61 & $0.009^{*}$ \\
\hline Mother ID & variance $=0.37$ & & \\
\hline
\end{tabular}


Table 4. Linear mixed model of the top parameters that explain variation in juvenile Florida Scrub-Jay rectrix hue. Variables were included based on their individual correlations with juvenile hue and their performance in a backward stepwise regression. Mother ID was included in the model as a random effect. The model explains a considerable about of variation in juvenile hue (conditional $R^{2}=0.39$ ), and significant parameters are indicated with asterisks.

\begin{tabular}{lcccc}
\hline Parameter & Estimate & SE & $t$ & $p$ \\
\hline Intercept & 0.17 & 0.10 & 1.72 & 0.09 \\
Sex & -0.39 & 0.12 & -3.26 & $0.001^{*}$ \\
Standardized Mass (year) & 0.28 & 0.06 & 4.42 & $<0.001^{*}$ \\
Group Size & -0.25 & 0.07 & -3.61 & $<0.001^{*}$ \\
Area of Oak Scrub & -0.07 & 0.08 & -0.91 & 0.36 \\
Group Size * Scrub & 0.22 & 0.06 & 3.38 & $<0.001^{*}$ \\
\hline Mother ID & variance $=0.20$ & & \\
\hline
\end{tabular}


Table 5. Generalized linear model of the top parameters that explain variation in adult Florida Scrub-Jay rectrix brightness. Variables were included based on their individual correlations with adult brightness and their performance in a stepwise regression. Unlike models for juvenile color, mother ID was not included in the model as a random effect because it yielded models with greater AIC. The model explains a considerable about of variation in adult brightness (marginal $R^{2}=0.56$ ), and significant parameters are indicated with asterisks.

\begin{tabular}{lcccc}
\hline Parameter & Estimate & SE & $t$ & $p$ \\
\hline Intercept & 0.30 & 0.16 & 1.93 & 0.06 \\
Juvenile Brightness & 0.74 & 0.12 & 6.40 & $<0.001^{*}$ \\
Sex & -0.18 & 0.24 & -0.74 & 0.46 \\
Adult Mass & -0.26 & 0.11 & -2.24 & $0.03^{*}$ \\
Microfilariae Infection (no) & -0.56 & 0.25 & -2.28 & $0.03^{*}$ \\
Group Size & 0.04 & 0.11 & 0.37 & 0.71 \\
Area of Oak Scrub & 0.19 & 0.11 & 1.68 & 0.10 \\
Group Size * Scrub & -0.18 & 0.10 & -176 & 0.09 \\
\hline
\end{tabular}


Table 6. Generalized linear model of the top parameters that explain variation in adult Florida Scrub-Jay rectrix chroma. Variables were included based on their individual correlations with adult chroma and their performance in a stepwise regression. Unlike models for juvenile color, mother ID was not included in the model as a random effect because it yielded models with greater AIC. The model explains a considerable about of variation in adult chroma (marginal $\mathrm{R}^{2}=0.46$ ), and significant parameters are indicated with asterisks.

\begin{tabular}{lcccc}
\hline Parameter & Estimate & SE & $t$ & $p$ \\
\hline Intercept & 0.33 & 0.28 & 1.17 & 0.25 \\
Juvenile Chroma & 0.39 & 0.12 & 3.29 & $0.002^{*}$ \\
Sex & 0.55 & 0.24 & 2.35 & $0.02^{*}$ \\
Standardized Mass (brood) & 0.33 & 0.12 & 2.88 & $0.006^{*}$ \\
Trypanosome Infection (no) & -0.52 & 0.24 & -2.20 & $0.03^{*}$ \\
Group Size & 0.21 & 0.13 & 1.63 & 0.11 \\
Area of Oak Scrub & 0.07 & 0.12 & 0.56 & 0.58 \\
Group Size * Scrub & -0.25 & 0.11 & -2.26 & $0.03^{*}$ \\
CORT Treatment: Experimental & -0.44 & 0.27 & -1.65 & 0.11 \\
CORT Treatment: Sham & 0.11 & 0.28 & 0.39 & 0.70 \\
\hline
\end{tabular}


Table 7. Generalized linear model of the top parameters that explain variation in adult Florida Scrub-Jay rectrix hue. Variables were included based on their individual correlations with adult hue and their performance in a stepwise regression. Unlike models for juvenile color, mother ID was not included in the model as a random effect because it yielded models with greater AIC. There was a considerable amount of variation in adult hue, and the model explains about $25 \%$ of the observed variation in adult hue (marginal $\mathrm{R}^{2}=0.24$ ). Significant parameters are indicated with asterisks.

\begin{tabular}{lcccc}
\hline Parameter & Estimate & SE & $t$ & $p$ \\
\hline Intercept & -0.06 & 0.27 & -0.22 & 0.82 \\
Juvenile Hue & 0.19 & 0.14 & 1.42 & 0.16 \\
Sex & -0.33 & 0.27 & -1.20 & 0.23 \\
Standardized Mass (brood) & -0.31 & 0.14 & -2.30 & $0.03^{*}$ \\
Group Size & -0.10 & 0.14 & -0.68 & 0.50 \\
Area of Oak Scrub & -0.09 & 0.15 & -0.60 & 0.55 \\
Group Size * Scrub & 0.25 & 0.13 & 1.98 & $0.05^{*}$ \\
CORT Treatment: Experimental & 0.45 & 0.31 & 1.47 & 0.14 \\
CORT Treatment: Sham & -0.19 & 0.33 & -0.58 & 0.56 \\
\hline
\end{tabular}


Table 8. Generalized linear model of the top parameters that explain variation in relative change in Florida Scrub-Jay rectrix brightness. Variables were included based on their individual correlations with change in brightness and their performance in a stepwise regression. The model explained 35\% of the observed variation in change in brightness across molts. Significant parameters are indicated with asterisks.

\begin{tabular}{lcccc}
\hline Parameter & Estimate & SE & $t$ & $p$ \\
\hline Intercept & 0.37 & 0.19 & 1.92 & 0.06 \\
Juvenile Mass & -0.30 & 0.13 & -2.28 & $0.03^{*}$ \\
Sex & -0.15 & 0.26 & -0.56 & 0.58 \\
Microfilariae Infection (no) & -0.72 & 0.28 & -2.55 & $0.01^{*}$ \\
Group Size & -0.03 & 0.14 & -0.20 & 0.85 \\
Area of Oak Scrub & 0.28 & 0.13 & 2.09 & $0.04^{*}$ \\
Group Size * Scrub & -0.27 & 0.12 & -2.24 & $0.03^{*}$ \\
\hline
\end{tabular}


Table 9. Generalized linear model of the top parameters that explain variation in relative change in Florida Scrub-Jay rectrix chroma. Variables were included based on their individual correlations with change in chroma and their performance in a stepwise regression. The model explained $24 \%$ of the observed variation in change in brightness across molts. Significant parameters are indicated with asterisks.

\begin{tabular}{lcccc}
\hline Parameter & Estimate & SE & $t$ & $p$ \\
\hline Intercept & 0.37 & 0.19 & 1.90 & 0.06 \\
Standardized Mass (brood) & 0.42 & 0.12 & 3.54 & $<0.001^{*}$ \\
Trypanosome Infection (no) & -0.54 & 0.25 & -2.21 & $0.03^{*}$ \\
\hline
\end{tabular}


Table 10. Generalized linear model of the top parameters that explain variation in relative change in Florida Scrub-Jay rectrix hue. Variables were included based on their individual correlations with change in hue and their performance in a stepwise regression. The model explained $23 \%$ of the observed variation in change in brightness across molts. Significant parameters are indicated with asterisks.

\begin{tabular}{lcccc}
\hline Parameter & Estimate & SE & $t$ & $p$ \\
\hline Intercept & -0.30 & 0.25 & -1.19 & 0.24 \\
Standardized Mass (brood) & -0.37 & 0.12 & -3.05 & $0.004^{*}$ \\
CORT Treatment: Experimental & 0.37 & 0.29 & 1.30 & 0.20 \\
CORT Treatment: Sham & -0.15 & 0.30 & -0.48 & 0.63 \\
Trypanosome Infection (no) & 0.26 & 0.25 & 1.03 & 0.31 \\
\hline
\end{tabular}


Table 11. Generalized linear model (binomial distribution, logit link function) of adult color variables that predict breeding fate. Males and females were assessed with separate models because of the significance of sex as a predictor in adult color models.

\begin{tabular}{llccccc}
\hline Sex & Parameter & $X^{2}$ & Estimate & SE & $Z$ & $p$ \\
\hline Males & Intercept & & -15.06 & 41.26 & -0.37 & 0.72 \\
& Adult Brightness & 2.01 & -1.10 & 0.82 & -1.34 & 0.16 \\
& Adult Chroma & 0.06 & 25.85 & 105.59 & 0.25 & 0.81 \\
& Adult Hue & 1.74 & 0.04 & 0.03 & 1.21 & 0.19 \\
\hline Females & Intercept & & -55.26 & 45.86 & -1.21 & 0.23 \\
& Adult Brightness & 0.30 & 0.41 & 0.77 & 0.54 & 0.58 \\
& Adult Chroma & 1.37 & 151.21 & 135.25 & 1.12 & 0.24 \\
& Adult Hue & 1.57 & 0.03 & 0.02 & 1.18 & 0.21 \\
\hline
\end{tabular}


Table 12. Generalized linear model (binomial distribution, logit link function) of juvenile color variables that predict breeding fate. Males and females were assessed with separate models because of the significance of sex as a predictor in adult color models.

\begin{tabular}{llccccc}
\hline Sex & Parameter & $X^{2}$ & Estimate & SE & $Z$ & $p$ \\
\hline Males & Intercept & & -50.67 & 34.82 & -1.46 & 0.15 \\
& Juvenile Brightness & 2.45 & -1.15 & 0.80 & -1.44 & 0.12 \\
& Juvenile Chroma & 2.77 & 151.55 & 96.67 & 1.57 & 0.09 \\
& Juvenile Hue & 3.62 & 0.05 & 0.03 & 1.61 & 0.05 \\
\hline \multirow{2}{*}{ Females } & Intercept & & 41.15 & 29.76 & 1.38 & 0.17 \\
& Juvenile Brightness & 1.51 & -0.82 & 0.69 & -1.18 & 0.22 \\
& Juvenile Chroma & 1.43 & -97.67 & 84.48 & -1.16 & 0.23 \\
& Juvenile Hue & 1.38 & -0.02 & 0.02 & -1.15 & 0.24 \\
\hline
\end{tabular}


Table 13. Generalized linear model (binomial distribution, logit link function) of relative change in color variables that predict breeding fate. Males and females were assessed with separate models because of the significance of sex as a predictor in adult color models. Significant predictors are marked with asterisks.

\begin{tabular}{llccccc}
\hline Sex & Parameter & $X^{2}$ & Estimate & SE & $Z$ & $p$ \\
\hline Males & Intercept & & -0.09 & 0.59 & -0.16 & 0.87 \\
& Change in Brightness & 0.04 & 0.01 & 0.07 & 0.19 & 0.85 \\
& Change in Chroma & 1.17 & -0.16 & 0.15 & -1.06 & 0.28 \\
& Change in Hue & 0.04 & -0.01 & 0.06 & -0.21 & 0.83 \\
\hline \multirow{2}{*}{ Females } & Intercept & & -0.18 & 0.57 & -0.31 & 0.76 \\
& Change in Brightness & 5.35 & 0.20 & 0.10 & 2.00 & $0.02^{*}$ \\
& Change in Chroma & 2.27 & 0.40 & 0.29 & 1.37 & 0.13 \\
& Change in Hue & 5.19 & 0.17 & 0.09 & 1.92 & $0.02^{*}$ \\
\hline
\end{tabular}




\section{FIGURES}

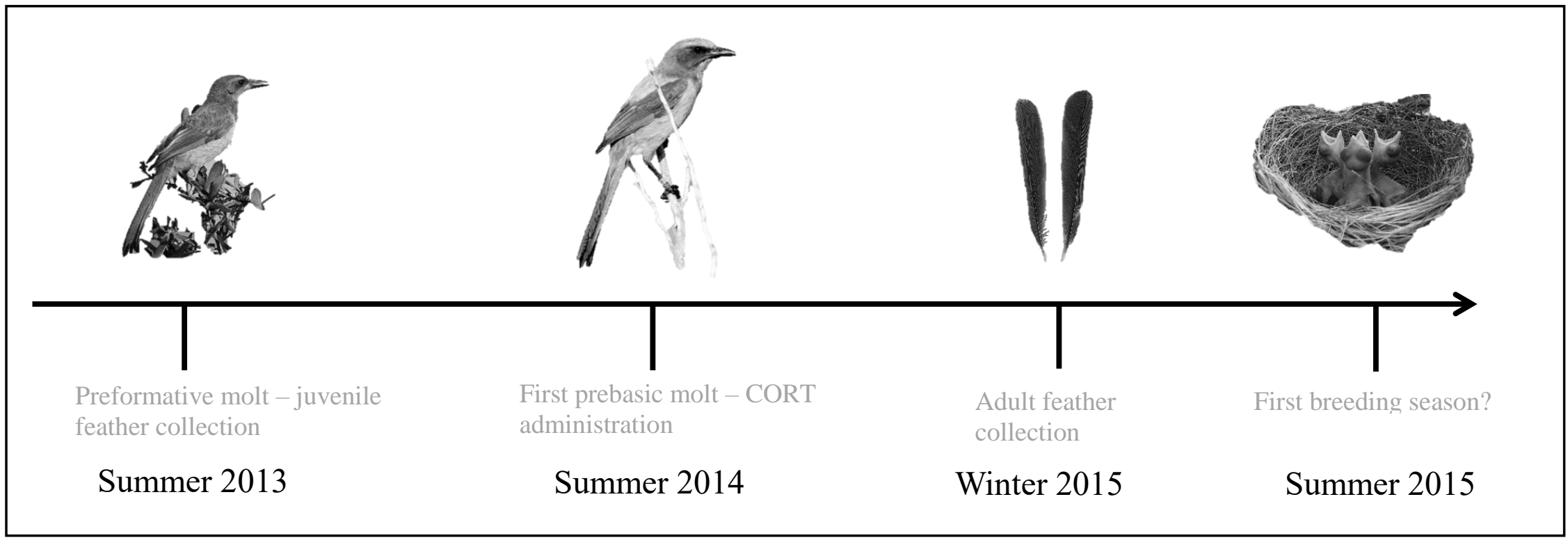

Figure 1. Timeline of data collection for the 2013 cohort. I collected the first tail feather samples once individuals had finished preformative molt and reached nutritional independence at 80-90 days of age. The following summer, when individuals were molting their first set of adult tail feathers, I administered CORT to randomly assigned birds for three weeks. I collected the second tail feather samples the following winter and monitored these individuals the next breeding season to determine who acquired breeding space and who remained a helper. I followed this time for the 2013-2015 cohorts. 

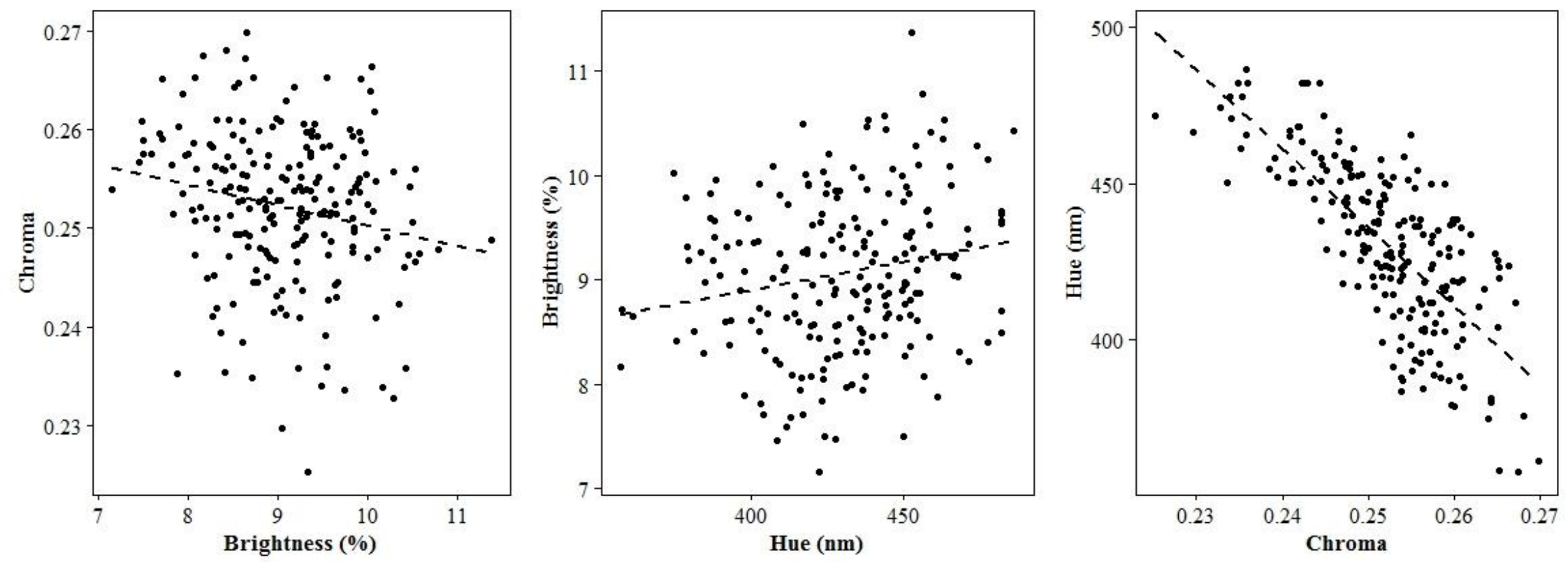

Figure 2. Correlations between the tri-stimulus color variables: brightness, chroma, and hue. Data represent juvenile color for the 2013-2015 yearly cohorts $(n=209)$. Dashed lines indicate significant correlations between chroma and brightness $(r=-0.199$, $p=0.004)$, brightness and hue $(\mathrm{r}=-0.737, \mathrm{p}<0.001)$, and hue and chroma $(\mathrm{r}=-0.746, \mathrm{p}<0.001)$. Brightness and hue were not significantly correlated. 


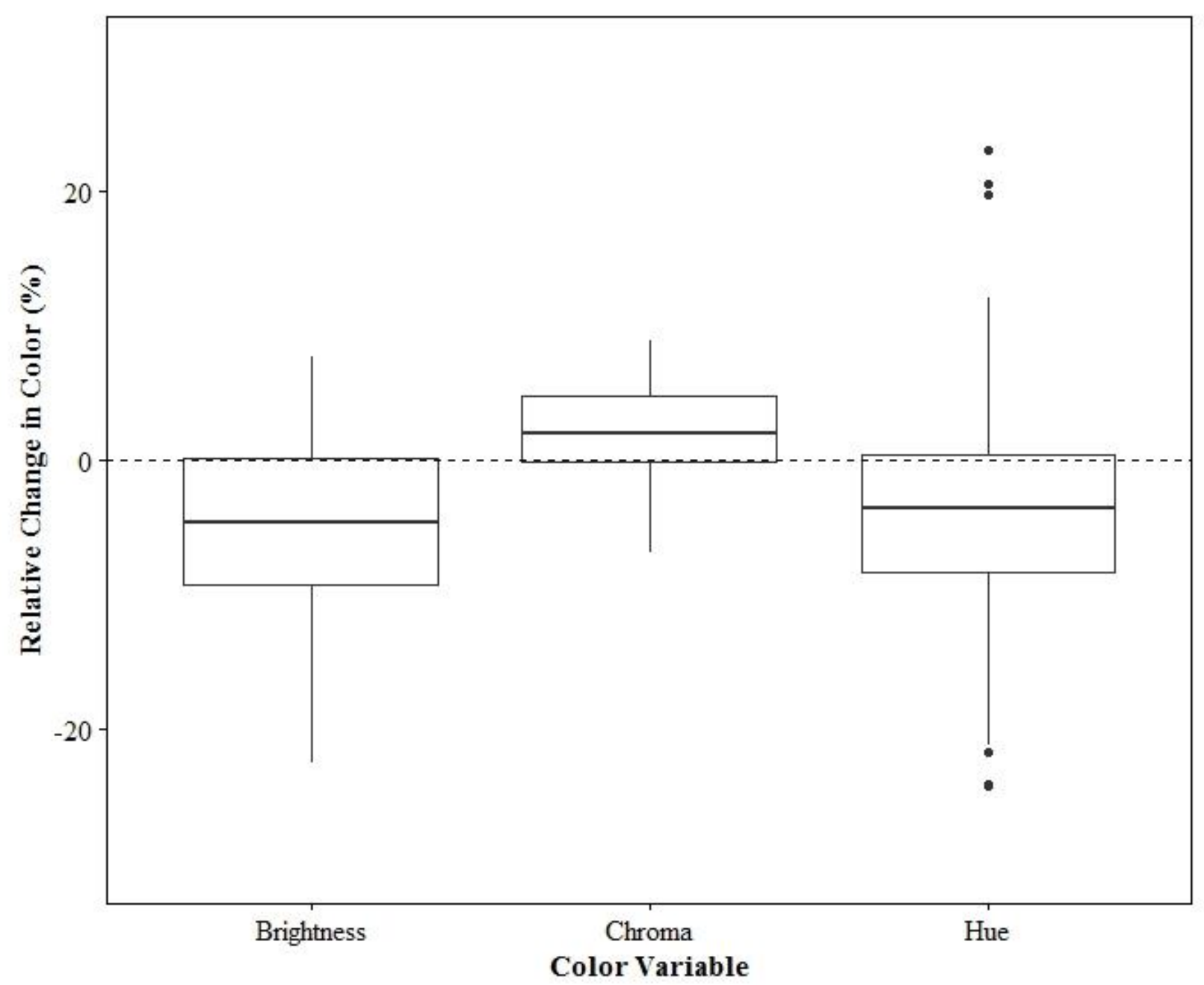

Figure 3. Relative change Florida Scrub-Jay rectrix color within individuals. Data represent surviving individuals from the 2013 and 2014 yearly cohorts $(n=57)$. 


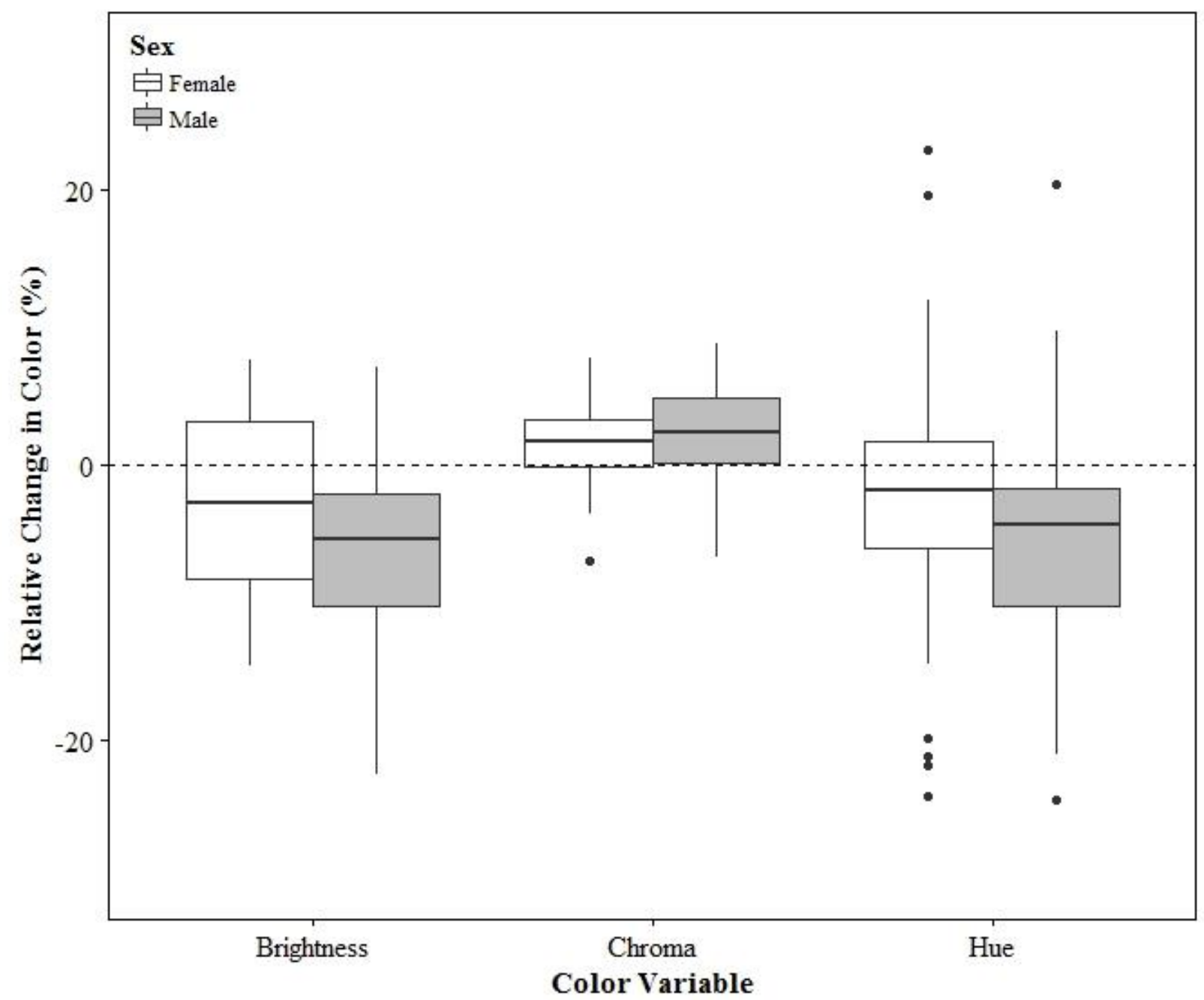

Figure 4. Relative change in Florida Scrub-Jay rectrix color within individuals for males and females. Data represent surviving individuals from the 2013 and 2014 yearly cohorts $(n=57)$. Relative change in color for males was not significantly different from that of females. 

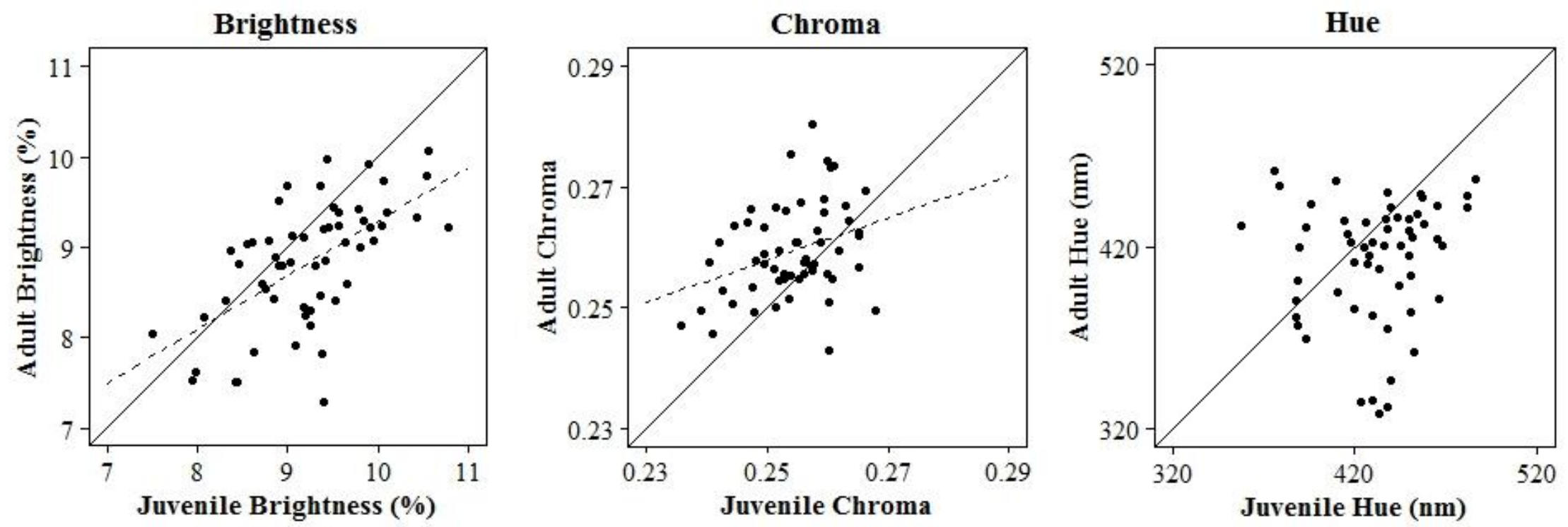

Figure 5. Juvenile vs. adult rectrix color in Florida Scrub-Jays within individuals $(n=57)$. Solid lines indicate a 1:1 ratio between juvenile and adult color, and dashed lines indicate significant correlations between adult and juvenile color for brightness $(r=0.603, p<0.001)$ and chroma $(r=0.333$, $\mathrm{p}=0.011$ ). Juvenile and adult hue were not significantly correlated. 

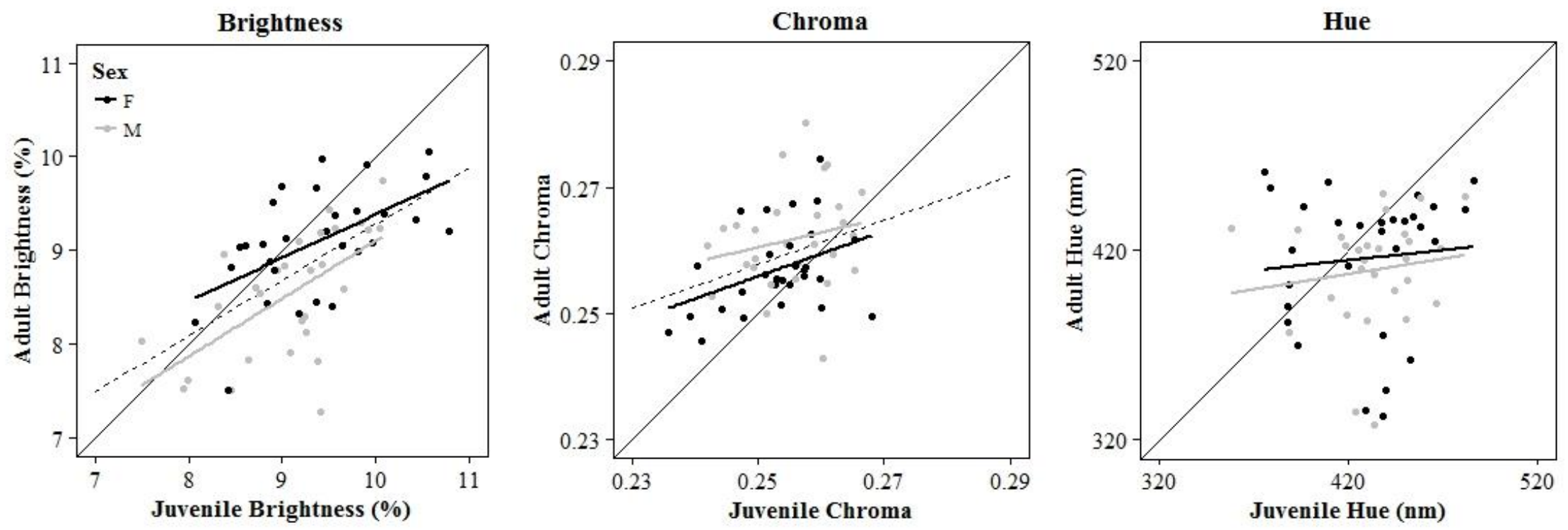

Figure 6. Juvenile vs. adult rectrix color in male and female Florida Scrub-Jays. The thin solid line indicates a 1:1 ratio where juvenile color is identical to adult color within individuals, and the dashed line represents the regression between juvenile and adult color for all individuals. Males (grey, $\mathrm{n}=28$ ) and females (black, $\mathrm{n}=29$ ) had similar distributions and regressions, and did not differ from the overall regression lines (dashed). Each point represents one individual $(\mathrm{n}=57)$. 

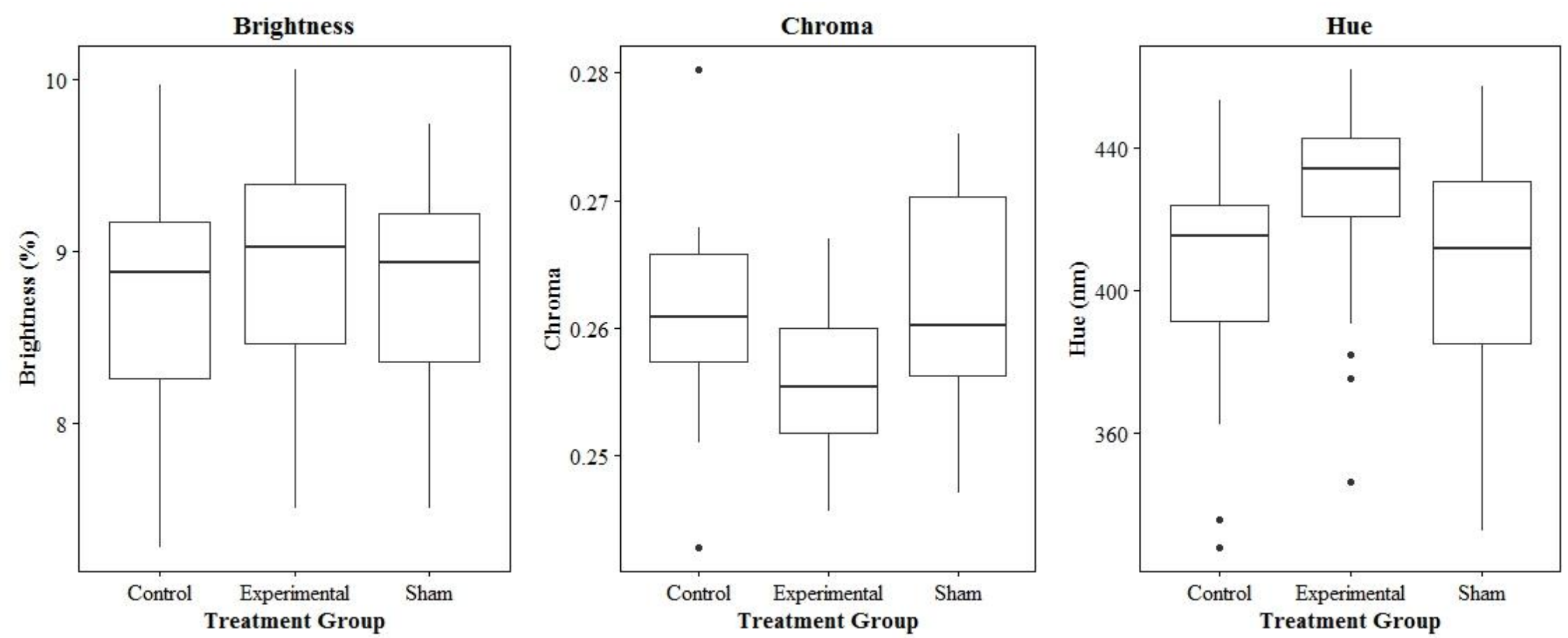

Figure 7. Adult Florida Scrub-Jay rectrix color by corticosterone administration treatment group. Individuals in the experimental treatment group received two doses of corticosterone each day for three weeks during molt, while sham group individuals received two sham control doses per day for three weeks. Control group individuals received nothing during molt. Individuals that received doses of corticosterone tended to reflect a smaller proportion of UV light than control and sham control individuals (GLM: texperimental $=-2.12 ; X^{2}=7.11, p=0.03$ ), with hues shifted toward longer wavelengths $\left(\mathrm{t}_{\text {experimental }}=1.85, X^{2}=4.69, \mathrm{p}=0.09\right)$. 

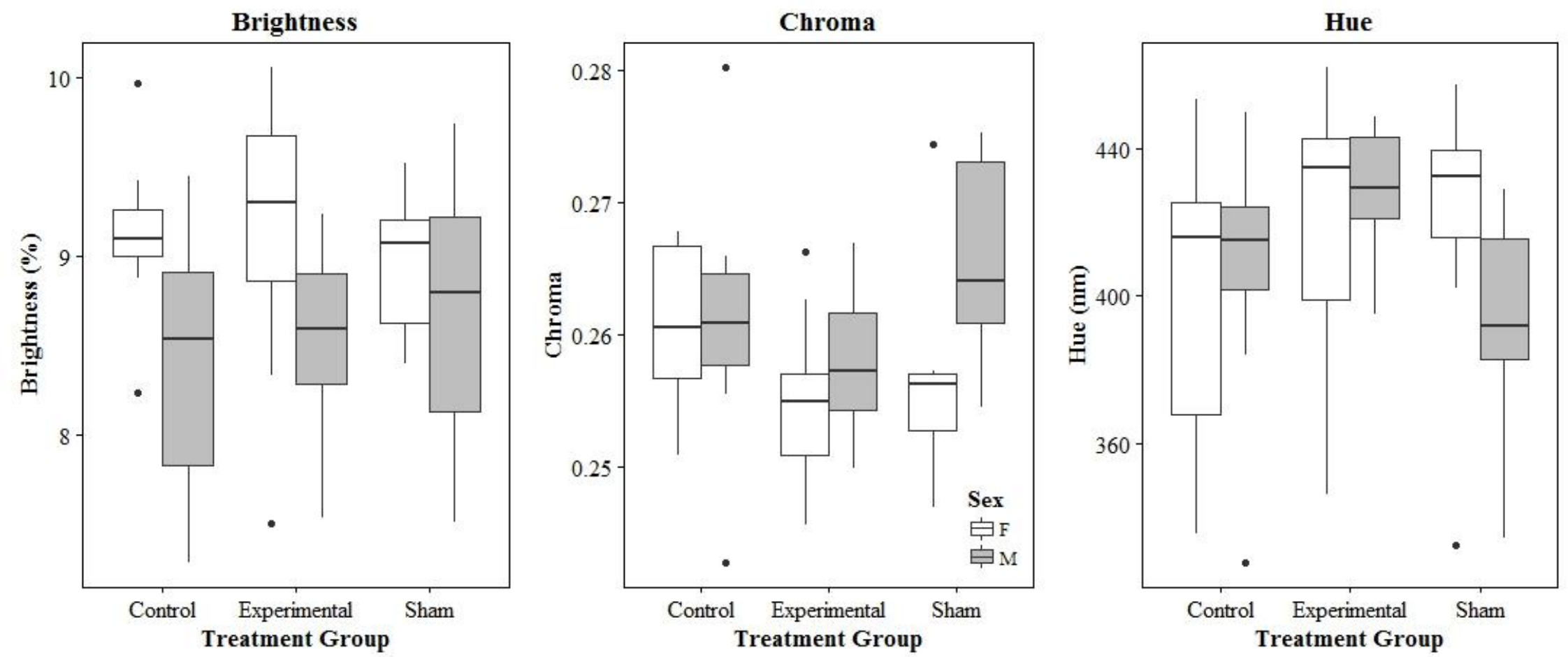

Figure 8. Male vs. female adult Florida Scrub-Jay rectrix color by corticosterone treatment group. Individuals were randomly assigned to treatment groups but were modified and switched when necessary to ensure equal sex ratios and distribution across the field site. Sample sizes are as follows: control (females $=8$, males $=11)$, experimental (females $=14$, males $=8$ ), and sham control $($ females $=7$, males $=9$ ). Corticosterone administration appears to affect both sexes equally, although the sham control group differences are puzzling. While there were no significant differences in color among treatment groups when controlling for sex, chroma tended to be lower for experimental group birds and hues tended to be shifted to longer wavelengths as well. 

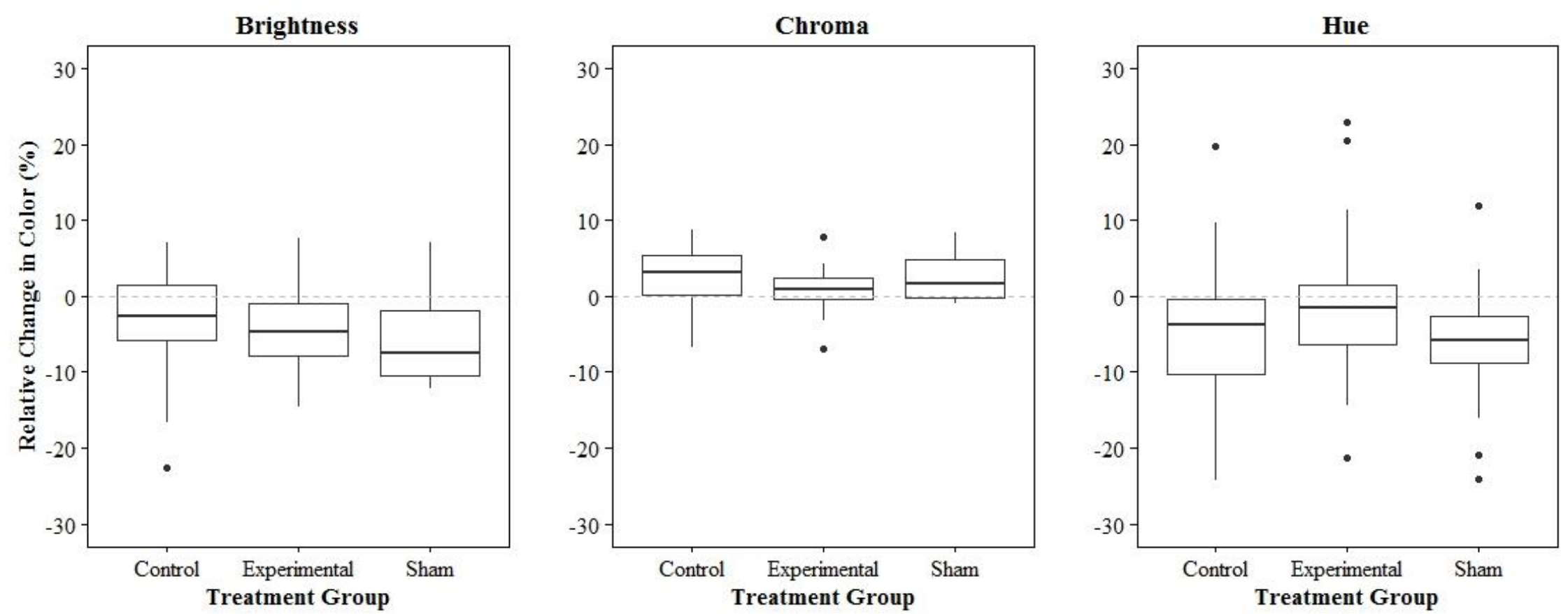

Figure 9. Relative change in Florida Scrub-Jay rectrix color across corticosterone treatment groups. Despite experimental birds having significantly different chroma and hue than control and sham individuals, there were no significant differences in relative change in brightness, chroma, and hue across treatment groups. 

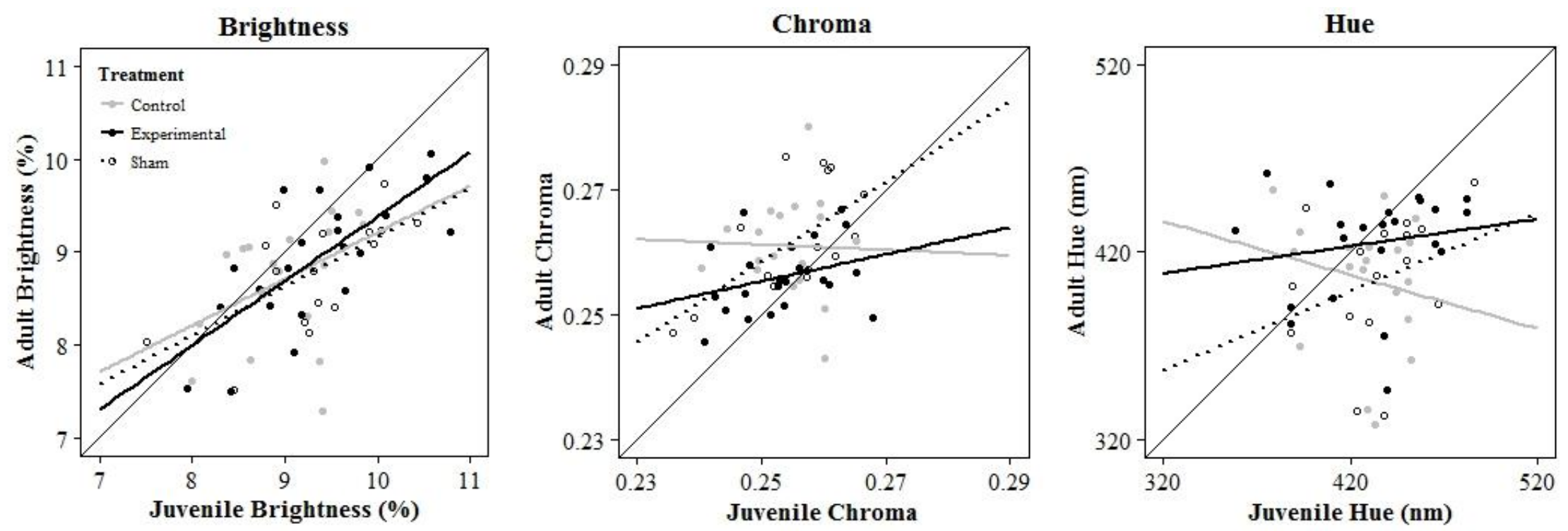

Figure 10. Juvenile vs. adult Florida Scrub-Jay rectrix color across corticosterone treatment groups: control ( $\mathrm{n}=19)$, experimental ( $\mathrm{n}=22)$, and sham control $(n=16)$. The thin solid line indicates a 1:1 ratio, where juvenile color is identical to adult color. Regression slopes are similar across all treatment groups for brightness, but correlations in chroma and hue appear to differ by treatment group. While individuals appear more scattered in chroma and hue, notably in the control group, experimental group birds had a reduced slope compared to sham control birds. 

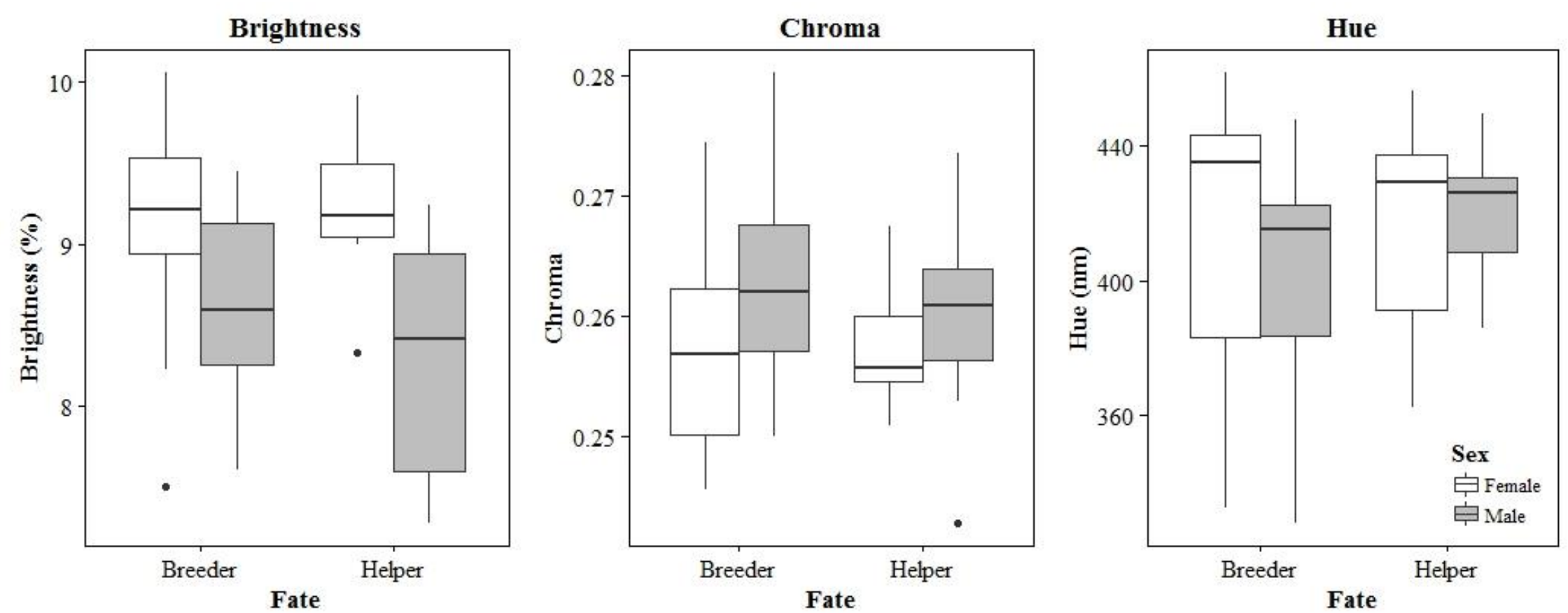

Figure 11. Adult Florida Scrub-Jay rectrix color for individuals that became breeders vs. individuals that remained helpers. Breeding fate was not significantly predicted by brightness, chroma, nor hue for adult males and females. Breeders and helpers had similar rectrix colors. 

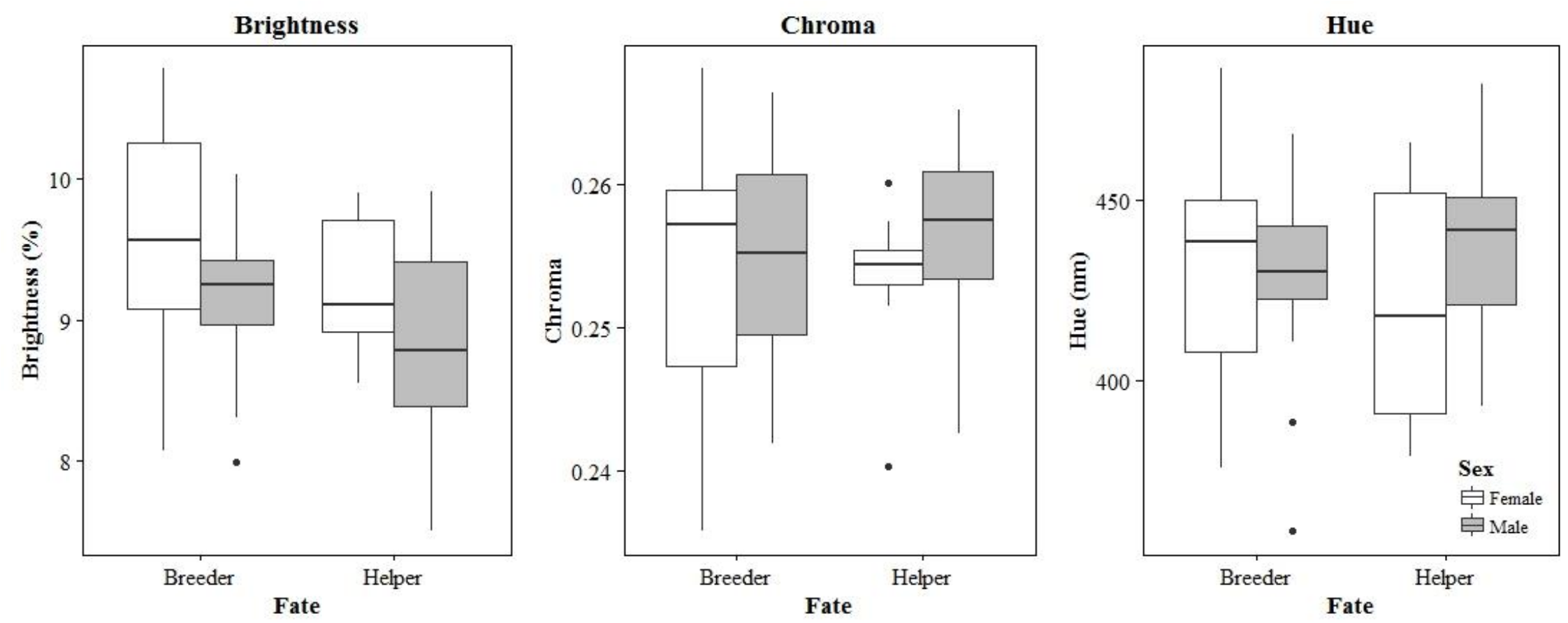

Figure 12. Juvenile Florida Scrub-Jay rectrix color for individuals that became breeders vs. individuals that remained helpers in their third year.

Juvenile brightness, chroma, and hue did not significantly predict breeding fate in females, although breeder females tended to be brighter, with a greater proportion of UV chroma at longer wavelengths than helpers. Both juvenile chroma and hue approached significance in a GLM predicting breeding fate in males $\left(X_{\text {chroma }}^{2}=2.77, \mathrm{p}=0.09 ; X_{\text {hue }}{ }^{2}=3.62, \mathrm{p}=0.06\right)$, but brightness was not a significant predictor. Males that acquired breeding space had a lower proportion of UV chroma and peak reflectance at shorter wavelengths as one-year-olds. While not significant, breeder males also tended to be brighter than helpers as one-year-olds. 

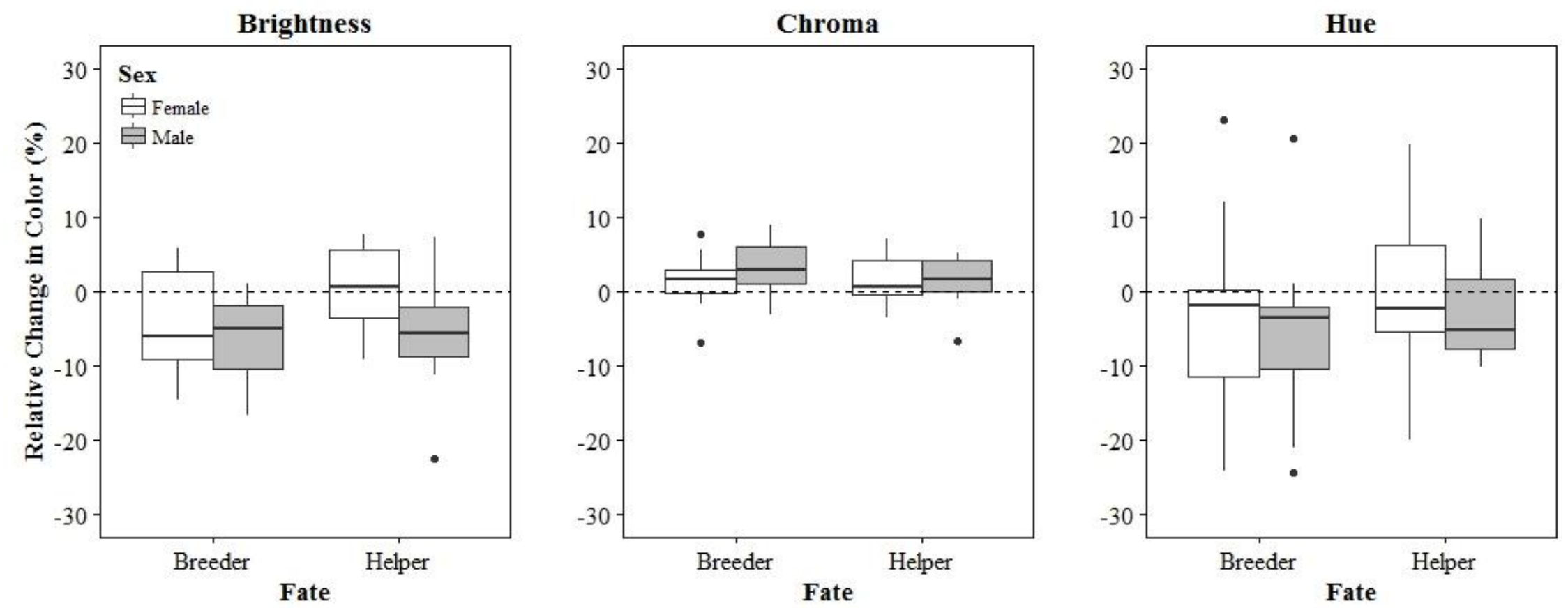

Figure 13. Relative change in Florida Scrub-Jay rectrix color for individuals that became breeders vs. individuals that remained helpers. Dashed lines indicate no change between juvenile and adult plumage. Breeding fate was not significantly predicted by change in brightness, chroma, nor hue for males. Female breeding space acquisition was significantly predicted by both change in brightness (GLM: $Z=2.00, X^{2}=5.35$, $\left.\mathrm{p}=0.02\right)$ and hue $\left(Z=1.92, X^{2}=5.19, p=0.02\right)$. Females that acquired breeding space experienced greater reductions in brightness than helper females, which showed very little relative change. Breeder females also tended to have hues shifted toward shorter UV wavelengths compared to helpers. 
APPENDICES 


\section{Appendix A: Effects of Individual Variables on Florida Scrub-Jay Rectrix Color}

Table A1. Correlations of individual environmental variables on juvenile Florida Scrub-Jay brightness. Each variable was regressed with juvenile brightness using GLM. Imputed data were used in cases where values were missing. Significant terms are indicated with asterisks.

\begin{tabular}{|c|c|c|c|c|c|c|}
\hline Parameter & Type & Estimate & SE & $t$ & $p$ & $\mathrm{R}^{2}$ \\
\hline Sex (male) & categorical $(\mathrm{M} / \mathrm{F})$ & -0.58 & 0.13 & -4.38 & $<0.001 *$ & 0.08 \\
\hline Juvenile Mass & continuous & 0.07 & 0.07 & 1.02 & 0.31 & 0.005 \\
\hline Standardized d11 Mass (year) & continuous & 0.04 & 0.07 & 0.61 & 0.54 & 0.002 \\
\hline Hematocrit & continuous & 0.10 & 0.07 & 1.39 & 0.16 & 0.01 \\
\hline Group Size & continuous & -0.01 & 0.07 & -0.18 & 0.86 & $<0.001$ \\
\hline Microfilariae Infection (no) & categorical (infected/non-infected) & 0.42 & 0.14 & 3.06 & $0.002 *$ & 0.05 \\
\hline Trypanosome Infection (no) & categorical (infected/non-infected) & 0.32 & 0.18 & 1.77 & 0.07 & 0.02 \\
\hline Area of Oak Scrub & continuous & 0.009 & 0.07 & 0.13 & 0.89 & $<0.001$ \\
\hline Area of TSF (2-9 years) & continuous & -0.13 & 0.07 & -1.85 & 0.06 & 0.02 \\
\hline Oak Scrub * Group Size & continuous & -0.08 & 0.07 & -1.07 & 0.28 & 0.006 \\
\hline Mother ID & categorical - random & & & \multicolumn{3}{|c|}{ variance $=0.25$} \\
\hline
\end{tabular}


Table A2. Correlations of individual environmental variables on juvenile Florida Scrub-Jay chroma. Each variable was regressed with juvenile chroma using GLM. Imputed data were used in cases where values were missing. Significant terms are indicated with asterisks.

\begin{tabular}{lcccccc}
\hline Parameter & Type & Estimate & SE & $t$ & $p$ & $\mathrm{R}^{2}$ \\
\hline Sex (male) & categorical (M/F) & 0.29 & 0.14 & 2.11 & $0.04^{*}$ & 0.02 \\
Juvenile Mass & continuous & -0.06 & 0.07 & -0.83 & 0.41 & 0.003 \\
Standardized d11 Mass (year) & continuous & -0.22 & 0.07 & -3.27 & $0.001^{*}$ & 0.05 \\
Hematocrit & continuous & -0.16 & 0.07 & -2.30 & $0.02^{*}$ & 0.03 \\
Group Size & continuous & 0.12 & 0.07 & 1.78 & 0.07 & 0.01 \\
Microfilariae Infection (no) & categorical (infected/non-infected) & 0.02 & 0.14 & 0.11 & 0.91 & $<0.001$ \\
Trypanosome Infection (no) & categorical (infected/non-infected) & -0.28 & 0.18 & -1.53 & 0.13 & 0.01 \\
Area of Oak Scrub & continuous & 0.002 & 0.07 & 0.03 & 0.97 & $<0.001$ \\
Area of TSF (2-9 years) & continuous & -0.03 & 0.07 & -0.44 & 0.66 & $<0.001$ \\
Oak Scrub * Group Size & continuous & -0.14 & 0.07 & -2.07 & $0.04 *$ & 0.04 \\
\hline Mother ID & categorical - random & & & \multicolumn{2}{c}{ variance $=0.34$} \\
\hline
\end{tabular}


Table A3. Correlations of individual environmental variables on juvenile Florida Scrub-Jay hue. Each variable was regressed with juvenile hue using GLM. Imputed data were used in cases where values were missing. Significant terms are indicated with asterisks.

\begin{tabular}{lcccccc}
\hline Parameter & Type & Estimate & SE & $t$ & $p$ & $\mathrm{R}^{2}$ \\
\hline Sex (male) & categorical (M/F) & -0.18 & 0.13 & -1.34 & 0.18 & 0.009 \\
Juvenile Mass & continuous & 0.10 & 0.07 & 1.37 & 0.17 & 0.008 \\
Standardized d11 Mass (year) & continuous & 0.29 & 0.07 & 4.31 & $<0.001^{*}$ & 0.08 \\
Hematocrit & continuous & 0.05 & 0.07 & 0.75 & 0.45 & 0.003 \\
Group Size & continuous & -0.24 & 0.07 & -3.63 & $<0.001^{*}$ & 0.06 \\
Microfilariae Infection (no) & categorical (infected/non-infected) & -0.13 & 0.14 & -0.92 & 0.36 & 0.004 \\
Trypanosome Infection (no) & categorical (infected/non-infected) & -0.07 & 0.18 & -0.39 & 0.70 & $<0.001$ \\
Area of Oak Scrub & continuous & -0.14 & 0.07 & -2.08 & $0.04 *$ & 0.02 \\
Area of TSF (2-9 years) & continuous & -0.16 & 0.07 & -2.35 & $0.02^{*}$ & 0.03 \\
Oak Scrub * Group Size & continuous & 0.19 & 0.07 & 2.90 & $0.004^{*}$ & 0.12 \\
\hline Mother ID & categorical - random & & & & variance $=0.24$ \\
\hline
\end{tabular}


Table A4. Correlations of individual environmental variables on adult Florida Scrub-Jay brightness.

\begin{tabular}{|c|c|c|c|c|c|c|}
\hline Parameter & Type & Estimate & $\mathrm{SE}$ & $t$ & $p$ & $\mathrm{R}^{2}$ \\
\hline Juvenile Brightness & continuous & 0.60 & 0.11 & 5.61 & $<0.001 *$ & 0.36 \\
\hline Sex (male) & categorical $(\mathrm{M} / \mathrm{F})$ & -0.82 & 0.24 & -3.38 & $0.001 *$ & 0.17 \\
\hline Adult Mass & continuous & -.022 & 0.13 & -1.67 & 0.10 & 0.05 \\
\hline Standardized d11 Mass (brood) & continuous & 0.11 & 0.13 & 0.83 & 0.41 & 0.01 \\
\hline Hematocrit & continuous & 0.09 & 0.13 & 0.68 & 0.50 & 0.008 \\
\hline Group Size & continuous & 0.23 & 0.13 & 1.78 & 0.08 & 0.05 \\
\hline Stepparent (yes) & categorical (yes/no) & 0.007 & 0.30 & 0.02 & 0.98 & $<0.001$ \\
\hline Microfilariae Infection (no) & categorical (infected/non-infected) & 0.06 & 0.32 & 0.19 & 0.85 & $<0.001$ \\
\hline Trypanosome Infection (no) & categorical (infected/non-infected) & 0.25 & 0.28 & 0.89 & 0.38 & 0.01 \\
\hline Area of Oak Scrub & continuous & 0.13 & 0.13 & 0.97 & 0.33 & 0.02 \\
\hline Area of TSF (2-9 years) & continuous & -0.08 & 0.13 & -0.62 & 0.54 & 0.007 \\
\hline Oak Scrub * Group Size & continuous & -0.07 & 0.13 & -0.56 & 0.58 & 0.06 \\
\hline CORT Treatment: Experimental & categorical (control, experimental, & 0.31 & 0.32 & 0.97 & 0.34 & 0.02 \\
\hline CORT Treatment: Sham & sham) & 0.11 & 0.34 & 0.33 & 0.75 & \\
\hline
\end{tabular}


Table A5. Correlations of individual environmental variables on adult Florida Scrub-Jay chroma.

\begin{tabular}{|c|c|c|c|c|c|c|}
\hline Parameter & Type & Estimate & $\mathrm{SE}$ & $t$ & $\bar{p}$ & $\mathrm{R}^{2}$ \\
\hline Juvenile Chroma & continuous & -0.33 & 0.13 & -2.58 & $0.01 *$ & 0.11 \\
\hline Sex & categorical $(\mathrm{M} / \mathrm{F})$ & 0.25 & 0.25 & 2.43 & $0.02 *$ & 0.10 \\
\hline Adult Mass & continuous & 0.15 & 0.13 & 1.16 & 0.25 & 0.02 \\
\hline Standardized d11 Mass (brood) & continuous & 0.18 & 0.13 & 1.37 & 0.18 & 0.03 \\
\hline Hematocrit & continuous & -0.16 & 0.13 & -1.17 & 0.25 & 0.02 \\
\hline Group Size & continuous & -0.004 & 0.13 & 0.03 & 0.98 & $<0.001$ \\
\hline Stepparent (yes) & categorical (yes/no) & 0.30 & 0.30 & 1.01 & 0.32 & 0.02 \\
\hline Microfilariae Infection (no) & categorical (infected/non-infected) & -0.18 & 0.32 & -0.57 & 0.57 & 0.006 \\
\hline Trypanosome Infection (no) & categorical (infected/non-infected) & -0.37 & 0.27 & -1.36 & 0.18 & 0.03 \\
\hline Area of Oak Scrub & continuous & 0.06 & 0.13 & 0.47 & 0.64 & 0.004 \\
\hline Area of TSF (2-9 years) & continuous & 0.05 & 0.13 & 0.40 & 0.69 & 0.003 \\
\hline Oak Scrub * Group Size & continuous & -0.16 & 0.13 & -1.17 & 0.25 & 0.03 \\
\hline CORT Treatment: Experimental & categorical (control, experimental, & -0.63 & 0.30 & -2.12 & $0.04 *$ & 0.12 \\
\hline CORT Treatment: Sham & sham) & 0.12 & 0.32 & 0.36 & 0.72 & \\
\hline Mother ID & categorical - random & & & \multicolumn{3}{|c|}{ variance $=0.14$} \\
\hline
\end{tabular}


Table A6. Correlations of individual environmental variables on adult Florida Scrub-Jay hue.

\begin{tabular}{|c|c|c|c|c|c|c|}
\hline Parameter & Type & Estimate & $\mathrm{SE}$ & $t$ & $p$ & $\mathrm{R}^{2}$ \\
\hline Juvenile Hue & continuous & 0.16 & 0.13 & 1.17 & 0.25 & 0.02 \\
\hline Sex (male) & categorical $(\mathrm{M} / \mathrm{F})$ & -0.18 & 0.27 & -0.67 & 0.50 & 0.008 \\
\hline Adult Mass & continuous & -0.14 & 0.13 & -1.04 & 0.30 & 0.02 \\
\hline Standardized d11 Mass (brood) & continuous & -0.25 & 0.13 & -1.91 & 0.06 & 0.06 \\
\hline Hematocrit & continuous & -0.006 & 0.14 & -0.04 & 0.96 & $<0.001$ \\
\hline Group Size & continuous & -0.06 & 0.13 & -0.47 & 0.64 & 0.004 \\
\hline Stepparent (yes) & categorical (yes/no) & -0.11 & 0.30 & -0.38 & 0.71 & 0.003 \\
\hline Microfilariae Infection (no) & categorical (infected/non-infected) & 0.30 & 0.32 & 0.94 & 0.35 & 0.02 \\
\hline Trypanosome Infection (no) & categorical (infected/non-infected) & 0.30 & 0.28 & 1.09 & 0.28 & 0.02 \\
\hline Area of Oak Scrub & continuous & -0.09 & 0.13 & 0.64 & 0.53 & 0.007 \\
\hline Area of TSF (2-9 years) & continuous & -0.05 & 0.13 & -0.39 & 0.70 & 0.003 \\
\hline Oak Scrub $*$ Group Size & continuous & 0.17 & 0.13 & 1.31 & 0.20 & 0.04 \\
\hline CORT Treatment: Experimental & categorical (control, experimental, & 0.57 & 0.31 & 1.85 & 0.07 & 0.08 \\
\hline CORT Treatment: Sham & sham) & -0.02 & 0.33 & -0.06 & 0.95 & \\
\hline Mother ID & categorical - random & & & \multicolumn{3}{|c|}{ variance $=0.04$} \\
\hline
\end{tabular}


Table A7. Correlations of individual environmental variables on relative change in Florida Scrub-Jay brightness.

\begin{tabular}{lcccccc}
\hline Parameter & Type & Estimate & SE & $t$ & $p$ & $\mathrm{R}^{2}$ \\
\hline Sex (male) & categorical (M/F) & -0.47 & 0.26 & -1.81 & 0.07 & 0.06 \\
Juvenile Mass & continuous & -0.38 & 0.12 & -3.02 & 0.004 & 0.14 \\
Standardized d11 Mass (brood) & continuous & -0.003 & 0.13 & -0.02 & 0.99 & $<0.001$ \\
Hematocrit & continuous & -0.14 & 0.13 & -1.05 & 0.30 & 0.02 \\
Group Size & continuous & 0.11 & 0.13 & 0.83 & 0.41 & 0.01 \\
Stepparent (yes) & categorical (yes/no) & 0.26 & 0.30 & 0.88 & 0.38 & 0.01 \\
Microfilariae Infection (no) & categorical (infected/non-infected) & -0.76 & 0.31 & -2.48 & $0.02^{*}$ & 0.10 \\
Trypanosome Infection (no) & categorical (infected/non-infected) & 0.16 & 0.28 & 0.58 & 0.57 & 0.006 \\
Area of Oak Scrub & continuous & 0.15 & 0.13 & 1.15 & 0.26 & 0.02 \\
Area of TSF (2-9 years) & continuous & -0.11 & 0.13 & -0.81 & 0.42 & 0.01 \\
Oak Scrub* Group Size & continuous & -0.34 & 0.12 & -2.76 & $0.008^{*}$ & 0.15 \\
CORT Treatment: Experimental & categorical (control, experimental, & -0.18, & 0.32 & -0.57 & 0.57 & 0.02 \\
CORT Treatment: Sham & sham) & -0.33 & 0.34 & -0.96 & 0.34 & \\
\hline
\end{tabular}


Table A8. Correlations of individual environmental variables on relative change in Florida Scrub-Jay chroma.

\begin{tabular}{|c|c|c|c|c|c|c|}
\hline Parameter & Type & Estimate & SE & $t$ & $p$ & $\mathrm{R}^{2}$ \\
\hline Sex (male) & categorical $(\mathrm{M} / \mathrm{F})$ & 0.25 & 0.27 & 0.94 & 0.35 & 0.02 \\
\hline Juvenile Mass & continuous & 0.18 & 0.13 & 1.33 & 0.19 & 0.03 \\
\hline Standardized d11 Mass (brood) & continuous & 0.40 & 0.12 & 3.25 & $0.002 *$ & 0.16 \\
\hline Hematocrit & continuous & 0.003 & 0.13 & 0.02 & 0.98 & $<0.001$ \\
\hline Group Size & continuous & 0.10 & 0.13 & 0.74 & 0.46 & 0.01 \\
\hline Stepparent (yes) & categorical (yes/no) & 0.13 & 0.30 & 0.43 & 0.67 & 0.003 \\
\hline Microfilariae Infection (no) & categorical (infected/non-infected) & 0.21 & 0.32 & 0.68 & 0.50 & 0.009 \\
\hline Trypanosome Infection (no) & categorical (infected/non-infected) & -0.47 & 0.27 & -1.74 & 0.08 & 0.05 \\
\hline Area of Oak Scrub & continuous & 0.04 & 0.13 & 0.31 & 0.76 & 0.002 \\
\hline Area of TSF (2-9 years) & continuous & 0.02 & 0.13 & 0.12 & 0.91 & $<0.001$ \\
\hline Oak Scrub * Group Size & continuous & -0.08 & 0.13 & -0.58 & 0.56 & 0.02 \\
\hline $\begin{array}{l}\text { CORT Treatment: Experimental } \\
\text { CORT Treatment: Sham }\end{array}$ & $\begin{array}{c}\text { categorical (control, experimental, } \\
\text { sham) }\end{array}$ & $\begin{array}{l}-0.47 \\
-0.03\end{array}$ & $\begin{array}{l}0.31 \\
0.34 \\
\end{array}$ & $\begin{array}{l}-1.50 \\
-0.09 \\
\end{array}$ & $\begin{array}{l}0.14 \\
0.93 \\
\end{array}$ & 0.05 \\
\hline
\end{tabular}


Table A9. Correlations of individual environmental variables on relative change in Florida Scrub-Jay hue.

\begin{tabular}{|c|c|c|c|c|c|c|}
\hline Parameter & Type & Estimate & SE & $t$ & $p$ & $\mathrm{R}^{2}$ \\
\hline Sex (male) & categorical $(\mathrm{M} / \mathrm{F})$ & -0.24 & 0.27 & -0.90 & 0.37 & 0.01 \\
\hline Juvenile Mass & continuous & -0.26 & 0.13 & -1.99 & 0.05 & 0.07 \\
\hline Standardized d11 Mass (brood) & continuous & -0.38 & 0.12 & -3.02 & $0.004 *$ & 0.14 \\
\hline Hematocrit & continuous & 0.005 & 0.13 & 0.04 & 0.97 & $<0.001$ \\
\hline Group Size & continuous & -0.02 & 0.13 & -0.18 & 0.86 & $<0.001$ \\
\hline Stepparent (yes) & categorical (yes/no) & 0.02 & 0.30 & 0.08 & 0.94 & $<0.001$ \\
\hline Microfilariae Infection (no) & categorical (infected/non-infected) & -0.15 & 0.31 & -0.50 & 0.62 & 0.005 \\
\hline Trypanosome Infection (no) & categorical (infected/non-infected) & 0.26 & 0.27 & 0.97 & 0.33 & 0.02 \\
\hline Area of Oak Scrub & continuous & 0.04 & 0.13 & 0.33 & 0.74 & 0.002 \\
\hline Area of TSF (2-9 years) & continuous & -0.02 & 0.13 & -0.15 & 0.88 & $<0.001$ \\
\hline Oak Scrub * Group Size & continuous & 0.13 & 0.13 & 1.00 & 0.32 & 0.02 \\
\hline $\begin{array}{l}\text { CORT Treatment: Experimental } \\
\text { CORT Treatment: Sham }\end{array}$ & $\begin{array}{c}\text { categorical (control, experimental, } \\
\text { sham) }\end{array}$ & $\begin{array}{l}0.37 \\
-0.16\end{array}$ & $\begin{array}{l}0.31 \\
0.34\end{array}$ & $\begin{array}{r}1.20 \\
-0.49\end{array}$ & $\begin{array}{l}0.24 \\
0.63\end{array}$ & 0.05 \\
\hline
\end{tabular}

